Article

\title{
Graphene/Carbon Nanotube Hybrid Nanocomposites: Effect of Compression Molding and Fused Filament Fabrication on Properties
}

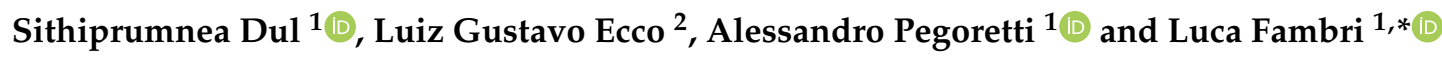 \\ 1 Department of Industrial Engineering and INSTM Research Unit, University of Trento, 38123 Trento, Italy; \\ sithiprumnea.dul@unitn.it (S.D.); alessandro.pegoretti@unitn.it (A.P.) \\ 2 Department of Mechanical Engineering, Federal University of Santa Catarina-UFSC, \\ Florianópolis 88040-900, SC, Brazil; luiz.ecco@labmat.ufsc.br \\ * Correspondence: luca.fambri@unitn.it; Tel.: +39-0461-282413
}

Received: 15 November 2019; Accepted: 19 December 2019; Published: 4 January 2020

\begin{abstract}
The present work reports on the production and characterization of acrylonitrile butadiene styrene (ABS) hybrid nanocomposite filaments incorporating graphene nanoplatelets (GNPs) and carbon nanotubes (CNTs) suitable for fused filament fabrication (FFF). At first, nanocomposites with a total nanofiller content of GNP and/or CNT of $6 \mathrm{wt} . \%$ and a GNP/CNT relative percentage ratio of 0,10 , $30,50,70$, and 100 were produced by melt compounding and compression molding. Their mechanical, electrical resistivity, and electromagnetic interference shielding effectiveness (EMI SE) properties were evaluated. The hybrid nanocomposites showed a linear increase in modulus and decrease in strength as a function of GNP content; on the other hand, the addition of CNT in hybrid nanocomposites determined a positive increase in electrical conductivity, but a potentially critical decrease of melt flow index. Due to the favorable compromise between processability and enhancement of performance (i.e., mechanical and electrical properties), the hybrid composition of 50:50 GNP/CNT was selected as the most suitable for the filament production of $6 \mathrm{wt} . \%$ carbonaceous nanocomposites. EMI SE of ABS-filled single CNT and hybrid GNP/CNT nanofillers obtained from compression molding reached the requirement for applications (higher than $-20 \mathrm{~dB}$ ), while slightly lower EMI SE values (in the range $-12 /-16 \mathrm{~dB}$ ) were obtained for FFF parts dependent on the building conditions.
\end{abstract}

Keywords: conductive composites; carbon nanotubes; graphene; electromagnetic interference shielding; mechanical properties

\section{Introduction}

Polymer nanocomposites with carbonaceous nanomaterial reinforcements are extensively investigated due to their remarkable performance including mechanical, electrical, and thermal properties. In particular, the use of nanomaterials can offer extraordinary structural and functional properties of polymers that can be tailored for broad application in many fields, but sometimes requires an adequate optimization of material processability. The nanocomposites could help the development of lightweight structural materials with functionalities that can be utilized for electronic components, micro-batteries, circuits, and electromagnetic shielding [1-5].

The extensive global development of novel electronic devices in many fields such as industrial, household, medical, science, military, and telecommunication cause electromagnetic pollution. Therefore, electromagnetic interference (EMI) is a major concern in modern society because it could affect the normal functionality of electronic devices and human health. Consequently, shielding is necessary for preventing electronics from undesired electromagnetic radiations associated with strategic 
systems utilized in the aerospace industry, aircraft, automobiles, flexible electronics, and wearable devices [6-9]. Conductive materials that are employed in shielding electromagnetic waves are typically metals and many forms of carbonaceous materials, e.g., carbon black, carbon nanotube (CNT), and graphite/graphene (GNP). However, utilizing metals in EMI shielding applications could cause drawbacks including an increase in weight, electrochemical corrosion, and more expensive processing methods [10-13]. Conductive polymers gained popularity in EMI shielding applications due to their relatively low cost, light weight, and easy processing. Because neat polymers possess poor EMI shielding properties, they are often compounded with conductive nanofillers via conventional processing methods (e.g., solvent casting [14-16], melt mixing followed by compression molding [17-20], and extrusion and injection [21]), as well as via additive manufacturing [2,22,23].

In the last decade, additive manufacturing (AM), also known as three-dimensional (3D) printing, was largely developed in both industry and research centers. An AM machine reads in data from a digital model and lays down or adds successive layers of liquid, powder, or sheet material, in a layer-upon-layer fashion, to fabricate a 3D object. This technology has several advantages such as the possibility to fabricate a final part without using auxiliary tool/molds and building complex geometric parts which are difficult via conventional methods [24-27]. Generally, additive manufacturing is more preferable for the relatively small-scale productions and it exhibits evident advantages with respect to subtractive manufacturing methodologies because of no residue after the process. There are several popular methods for AM such as stereolithography (SLA), using a focused ultraviolet (UV) laser beam to photopolymerize the uncured resin layer by layer, selective laser sintering (SLS), using a scanning laser beam to sinter the powdered materials at the cross-sections, and fused filament fabrication (FFF), using a small extruder to melt and deposit a thermoplastic filament. The FFF technique, which is most dominant in AM methods due to its low cost and easy use, requires fewer post-processing steps, and a large variety of materials can be used. The process is a simple extrusion of filaments in the molten state through a heated nozzle (350-600 $\mu \mathrm{m})$ to create 3D objects via layer-by-layer deposition in the horizontal plane (XY plane) [26].

The development of nanocomposite materials could be a way to improve the properties of components produced by FFF. Some studies reported that combining two nanofillers (e.g., carbon nanotubes and graphene) could induce a synergistic effect in various matrices such as epoxy [28-30], polylactic acid (PLA) [31-33], and thermoplastic polyurethanes (TPUs) [34]. The mechanical properties and the thermal and electrical conductivities of double-filler nanocomposites could exhibit higher values than those of single-filler nanocomposites, due to the formation of a co-supporting network of both fillers. However, the synergistic effect of nanofillers is not completely understood scientifically. Very recent works reported hybrid graphene nanoplatelet (GNP)/carbon nanotube (CNT) nanofillers for the FFF technique in different matrices, such as PLA [31-33] and polyether ether ketone (PEEK) [35]. PLA-carbon based nanocomposites derived from the FFF technique were also investigated in terms of electrical and thermal conductivity and electromagnetic shielding behavior. In particular, taking into consideration the $\mathrm{T}_{\mathrm{g}}$ of the PLA matrix, a specific approach to compensate for the temperature effect on the resistivity of a PLA conductive sample in the range $20-50{ }^{\circ} \mathrm{C}$ was discussed [36]. In order to enlarge the number of application fields with high-performance properties, especially for high temperature, a different approach was recently proposed with processing and 3D printing of PEEK filled with GNP/CNT up to $380^{\circ} \mathrm{C}$. Tensile properties, electrical and thermal conductivity, and tribological properties of 3D-printed nanocomposites were properly studied and considered for aerospace applications [35]. However, no research reported a hybrid GNP/CNT nanofiller in an acrylonitrile butadiene styrene (ABS) matrix, whose temperature range of applications goes up to $80^{\circ} \mathrm{C}$. In particular, the electromagnetic shielding behavior of 3D-printed samples remains to be investigated.

Our previous research focused on the development of nanocomposite filaments within carbonaceous nanofillers (i.e., graphene, carbon nanotube, and carbon black) suitable for the FFF technique with characterizations of the structure and physical properties [22,23,37-39]. Both graphene and carbon nanotubes were successfully utilized in the FFF process, determining positive effects at 
different levels $[37,39]$. The incorporation of CNT provided not only a high increase in electrical conductivity, but also a severe increase in the viscosity of materials that consequently required a high-temperature FFF process $\left(280^{\circ} \mathrm{C}\right)$. On the other hand, GNP was found not effective for resistivity reduction, but GNP/ABS nanocomposites could maintain better processability due to their relatively higher melt flow index. In our previous work, we concluded that proper combinations of CNT and GNP at a suitable fraction (e.g., $6 \mathrm{wt} . \%$ in the hybrid) could offer a possible compromise between relatively easy processability and an acceptable enhancement of performance (i.e., mechanical and specific electrical properties) for applications where polymeric materials with low electrical resistivity are required [40].

The present work focuses on the preparation and characterization of ABS nanocomposites based on a hybrid composition of GNP and CNT, suitable for FFF 3D printing. In a preliminary investigation, the total amount of nanofiller of nanocomposites fixed at $6 \mathrm{wt} . \%$ with the variation of GNP/CNT relative ratio was produced by compression molding. Optimal compositions were selected for extrusion and the FFF technique, and the produced single-filler and hybrid nanocomposites were characterized under mechanical, electrical, and electromagnetic interference shielding testing.

\section{Materials and Methods}

\subsection{Materials}

Acrylonitrile butadiene styrene (ABS) Sinkral ${ }^{\circledR} \mathrm{F} 322$ (melt flow rate of $14 \mathrm{~cm}^{3} / 10 \mathrm{~min}$ at $220^{\circ} \mathrm{C} / 10 \mathrm{~kg}$; density of $1.04 \mathrm{~g} / \mathrm{cm}^{3}$ ) used in this study was supplied by Versalis S.p.A. (Mantova, Italy) [41]. Before processing, ABS pellets were dried at $80{ }^{\circ} \mathrm{C}$ in a vacuum oven for at least $2 \mathrm{~h}$. The selected carbon nanoparticles, graphene nanoplatelets and carbon nanotubes, are presented in Table 1 with details of their dimensions and physical characteristics according to the manufacturer datasheet.

Table 1. Properties of commercial grades of graphene nanoplatelets (GNPs) and multi-walled carbon nanotubes (CNTs) according to the manufacturer.

\begin{tabular}{|c|c|c|c|c|c|c|}
\hline Nanoparticle & $\begin{array}{l}\text { Length/Width } \\
(\mu \mathrm{m})\end{array}$ & $\begin{array}{c}\text { Diameter/Thickness } \\
\text { (nm) }\end{array}$ & $\begin{array}{c}\text { Surface } \\
\text { Area } \\
\left(\mathrm{m}^{2} / \mathrm{g}\right)\end{array}$ & $\begin{array}{c}\text { Carbon } \\
\text { Purity } \\
(\%)\end{array}$ & $\begin{array}{l}\text { Density } \\
\left(\mathrm{g} / \mathrm{cm}^{3}\right)\end{array}$ & Manufacturer \\
\hline xGnP-M5 & 5 & $6-8$ & $120-150$ & $>99.5$ & $2.06 \pm 0.03 *$ & XG sciences, USA [42] \\
\hline MWCNT-NC7000 & 1.5 & 9.5 & $250-300$ & $>90$ & $2.15 \pm 0.03^{* *}$ & Nanocyl, Belgium [43] \\
\hline
\end{tabular}

* Data extracted from Reference [44]; ** data extracted from Reference [39].

The basic quality assessment data of nanofillers are available in the technical data sheets for GNP [42] and CNT [43], as well as in some literature publications. In particular, Raman spectra and X-ray Diffraction (XRD) characterization were reported for GNP [42,45] and CNT [46]. TEM images of both GNP and CNT were also illustrated in our previous publication [40]. Moreover, TEM micrographs of MWCNT-NC7000 in an ABS nanocomposite evidenced a certain level of orientation in filaments [47].

\subsection{Material Processing and Sample Preparation}

\subsubsection{Compounding}

Various GNP/CNT ratio nanofillers at a total concentration fixed at $6 \mathrm{wt.} \%$, as detailed in Table 2, were mixed with neat ABS by melt compounding in a counter-rotating Thermo-Haake Polylab Rheomix internal mixer (Thermo Haake, Karlsruhe, Germany) at a temperature of $190^{\circ} \mathrm{C}$, with a rotor speed of $90 \mathrm{rpm}$, for $15 \mathrm{~min}$. Neat ABS was also processed under the same conditions. 
Table 2. Designation and formulation of acrylonitrile butadiene styrene (ABS) hybrid nanocomposites at different GNP/CNT ratios.

\begin{tabular}{ccccc}
\hline Sample & ABS (wt.\%) & GNP (wt.\%) & CNT (wt.\%) & GNP/CNT Relative Ratio \\
\hline ABS & 100 & 0 & 0 & $0: 0$ \\
GNP/CNT (100:0) & 94 & 6.0 & 0.0 & $100: 0$ \\
GNP/CNT (90:10) & 94 & 5.4 & 0.6 & $90: 10$ \\
GNP/CNT (70:30) & 94 & 4.2 & 1.8 & $70: 30$ \\
GNP/CNT (50:50) & 94 & 3.0 & 3.0 & $50: 50$ \\
GNP/CNT (30:70) & 94 & 1.8 & 4.2 & $30: 70$ \\
GNP/CNT (10:90) & 94 & 0.6 & 5.4 & $10: 90$ \\
GNP/CNT (0:100) & 94 & 0.0 & 6.0 & $0: 100$ \\
\hline
\end{tabular}

\subsubsection{Compression Molding (CM)}

Compounded batches of about $50 \mathrm{~g}$ were produced for each composition. The compounded materials were hot-pressed at $190{ }^{\circ} \mathrm{C}$ in a Carver Laboratory press (Carver, Inc., Wabash, IN, USA) for 10 min under a pressure of $3.9 \mathrm{MPa}$ to obtain square plates with dimensions $160 \times 160 \times 1.2 \mathrm{~mm}^{3}$ (for mechanical and resistivity tests) and $120 \times 120 \times 2 \mathrm{~mm}^{3}$ (for electromagnetic interference shielding effectiveness (EMI SE) analysis).

\subsubsection{Filament Extrusion}

Compounded materials were also used to feed a Thermo Haake PTW16 intermeshing co-rotating twin-screw extruder produced by Thermo Haake, Karlsruhe, Germany (screw diameter $=16 \mathrm{~mm} ; L / D$ ratio $=25$; rod die diameter $1.80 \mathrm{~mm}$ ). The processing temperature profile gradually increased from $T_{1}$ $=180^{\circ} \mathrm{C}$ to $T_{2}=205^{\circ} \mathrm{C}, T_{3}=210{ }^{\circ} \mathrm{C}, T_{4}=215^{\circ} \mathrm{C}$, and $T_{5}=220^{\circ} \mathrm{C}$ (rod die). The screw rotation speed was fixed at $5 \mathrm{rpm}$, and collection rate was regulated (about $1.0 \mathrm{~m} / \mathrm{min}$ ) by using a take-up unit Thermo Electron Type 002-5341 in order to obtain a final diameter of the extruded filament of $1.75 \pm 0.05 \mathrm{~mm}$ (see Figure 1).

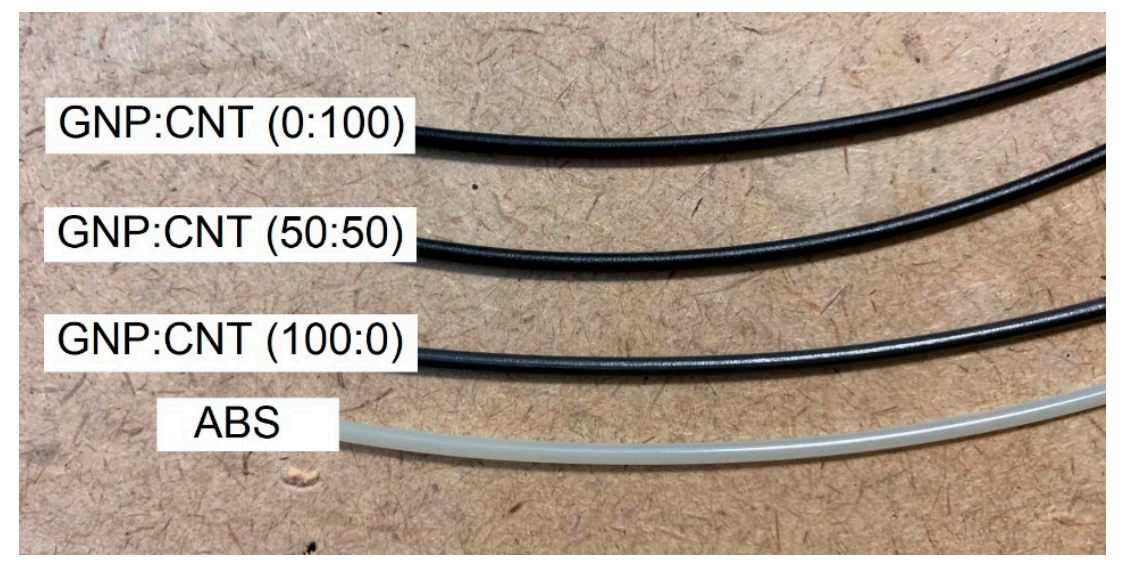

Figure 1. Filaments of neat acrylonitrile butadiene styrene (ABS), and graphene nanoplatelet (GNP)/multi-walled carbon nanotube (CNT) (100:0), GNP/CNT (50:50), and GNP/CNT (0:100) nanocomposites at $6 \mathrm{wt}$ \% of nanofiller.

\subsubsection{FFF Printed Sample Preparation}

The 3D-printed specimens were manufactured by a prototype 3D printer for high-temperature processing, Sharebot HT Next Generation desktop 3D printer (Sharebot NG, Nibionno, LC, Italy), fed with the filaments extruded as described in the previous paragraph. The 3D-printed samples were built in three configurations, horizontal concentric (HC), horizontal $45^{\circ}$ angle (H45), and perpendicular concentric (PC), as detailed in our previous publication [39]. In summary, all the specimens were 
3D-printed using the following printing parameters: object infill 100\%; no raft; nozzle diameter $0.40 \mathrm{~mm}$; bed temperature $110^{\circ} \mathrm{C}$; layer height $0.20 \mathrm{~mm}$; raster angle $\left(0^{\circ} / 0^{\circ}\right)$ for $\mathrm{HC}$ and $\mathrm{PC}$ and raster angle $\left(+45^{\circ} /-45^{\circ}\right)$ for H45; infill speed $40 \mathrm{~mm} / \mathrm{s}$ for $\mathrm{HC}$ and $\mathrm{H} 45$ and $16 \mathrm{~mm} / \mathrm{s}$ for PC specimens. The 3D-printed parts were manufactured at a nozzle temperature of $280^{\circ} \mathrm{C}$ for the CNT nanocomposite, and $250^{\circ} \mathrm{C}$ for the ABS matrix, GNP, and hybrid GNP/CNT nanocomposites.

\subsection{Testing Techniques}

\subsubsection{Scanning Electron Microscopy (SEM)}

Nanocomposites were fractured in liquid nitrogen and their representative fracture surfaces at different levels of magnification were observed by a Carl Zeiss AG Supra 40 field-emission scanning electron microscope (FE-SEM) (Carl Zeiss AG, Oberkochen, Germany) at an acceleration voltage of $5 \mathrm{kV}$.

\subsubsection{Melt Flow Index (MFI)}

The MFI measurements were performed according to the ASTM D 1238 standard (procedure A), using a Kayeness Co. model 4003DE capillary rheometer (Morgantown, PA, USA), at $220^{\circ} \mathrm{C} / 10 \mathrm{~kg}$ with a pre-heating and compaction time of about $5 \mathrm{~min}$ on samples with a mass of about $5 \mathrm{~g}$ cut from compression molded plates.

\subsubsection{Tensile Test}

Uniaxial tensile tests were performed at room temperature using an Instron ${ }^{\circledR} 5969$ electromechanical tester (Norwood, MA, USA) equipped with a 50-kN load cell. Strength and strain at break values were determined at a crosshead speed of $10 \mathrm{~mm} / \mathrm{min}$ as an average of at least three replicates. Three categories of samples were investigated: (1) compression molded (CM) samples ISO 527 type 1BA dumbbell (gauge length $30 \mathrm{~mm}$; thickness $1.2 \mathrm{~mm}$ ); (2) filaments (gauge length $100 \mathrm{~mm}$; diameter $1.75 \mathrm{~mm}$ ); (3) 3D-printed samples (HC, H45, and PC), ISO 527 type 5A dumbbell (gauge length $25 \mathrm{~mm}$; thickness $2 \mathrm{~mm}$ ).

The elastic modulus of CM and 3D-printed specimens was evaluated at a crosshead speed of $1 \mathrm{~mm} /$ min using an electrical extensometer Instron ${ }^{\circledR}$ model 2620-601 (Norwood, MA, USA) with a gauge length of $12.5 \mathrm{~mm}$. The elastic modulus of the filament was measured at a crosshead speed of $10 \mathrm{~mm} / \mathrm{min}$ without an extensometer with a gauge length of $100 \mathrm{~mm}$, taking the system compliance into account. According to the ISO 527 standard, the elastic modulus was determined as a secant value between strain levels of $0.05 \%$ and $0.25 \%$.

\subsubsection{Electrical Resistivity Test}

For samples with an electrical resistivity higher than $10^{7} \Omega \cdot \mathrm{cm}$, the volume resistivity $\rho$ was determined according to ASTM D257 using a Keithley 6517A electrometer/high-resistance meter (Beaverton, OR, USA) and an 8009 resistivity test fixture at room temperature. In this test, a constant voltage of $100 \mathrm{~V}$ was applied to square samples of $64 \times 64 \times 1.2 \mathrm{~mm}^{3}$.

For moderately conductive materials $\left(\rho<10^{7} \Omega \cdot \mathrm{cm}\right)$, the electrical resistivity test was measured according to the ASTM D4496-04 standard with a four-point contact configuration. Each specimen was subjected to a voltage of $5 \mathrm{~V}$ generated by a direct current (DC) power supply IPS303DD produced by ISO-TECH (Milan, Italy). Simultaneously, the current flow on the samples was recorded between external electrodes by using an ISO-TECH IDM 67 Pocket Multimeter electrometer (ISO-TECH, Milan, Italy). Compression molding (CM), filaments, and 3D-printed samples were tested with a length of $25 \mathrm{~mm}$ and different cross-section (rectangular specimens $6 \times 1.2 \mathrm{~mm}^{2}$ for $\mathrm{CM}$ and $6 \times 2 \mathrm{~mm}^{2}$ for 3D-printed sample; diameter of $1.75 \mathrm{~mm}$ for filament). Average values of resistivity from at least three replicates were reported. A conductive silver paint was applied to the surface of 3D-printed samples in 
order to obtain good electrical contact. The electrical volume resistivity of the samples was determined by Equation (1).

$$
\rho=R \times \frac{A}{L}
$$

where $R$ is the electrical resistance, $A$ is the is the cross-section of the specimen, and $L$ is the distance between the internal electrodes (i.e. $3.69 \mathrm{~mm}$ ). All the reported electrical conductivity and resistivity values were volume electrical conductivity and volume resistivity, taking into account the thickness of samples.

\subsubsection{Electromagnetic Interference Shielding Effectiveness (EMI SE)}

The electromagnetic interference shielding capabilities of $\mathrm{CM}$ and 3D-printed samples were measured using an Agilent Technology PNA series network analyzer (N5230C Agilent PNA-L, Santa Clara, CA) and a standard rectangular waveguide in the X-band frequency range (8.2-12.4 GHz). The analysis was performed on compression molded and FFF samples with a dimension $45 \times 45$ $\times 2 \mathrm{~mm}^{3}$, and the S-parameters $\left(\mathrm{S}_{11}, \mathrm{~S}_{22}, \mathrm{~S}_{12}, \mathrm{~S}_{21}\right)$ were recorded over the $\mathrm{X}$-band frequency range, as detailed in the literature $[23,44]$. The contributions of reflection $\left(\mathrm{SE}_{\mathrm{R}}\right)$ and absorption $\left(\mathrm{SE}_{\mathrm{A}}\right)$ to the total EMI SE of the composites were investigated, while the effect of multiple reflections $\left(\mathrm{SE}_{\mathrm{M}}\right)$ was neglected. At least three specimens were tested for each sample, and the standard deviations were calculated.

\section{Results and Discussions}

\subsection{Melt Flow Index and Morphology}

The flow properties of hybrid nanocomposite formulations at a fixed total amount of filler $(6 \mathrm{wt} . \%)$ as a function of the different fraction ratios is presented in Figure 2. The MFI values of nanocomposites significantly decreased with the CNT content. By optimizing the enhancement of properties (mechanical and electrical properties) and processability, the selected composition of 50:50 of $6 \mathrm{wt} . \%$ of hybrid nanocomposite was extruded into filaments for FFF. It is worthwhile to note that the GNP/CNT (50:50) nanocomposite could be 3D-printed at $250^{\circ} \mathrm{C}$, whereas the GNP/CNT (0:100) nanocomposite required a processing temperature of $280^{\circ} \mathrm{C}$.

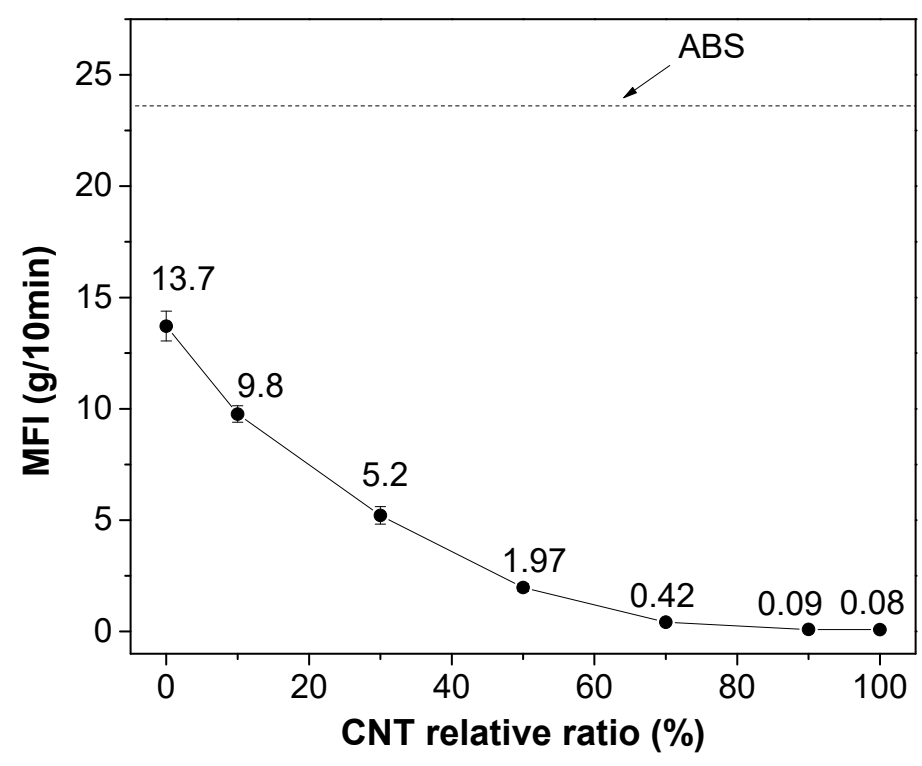

Figure 2. Melt flow index (MFI) $\left(220^{\circ} \mathrm{C} / 10 \mathrm{~kg}\right)$ of $6 \mathrm{wt} . \% \mathrm{GNP} / \mathrm{CNT}$ nanocomposites with different CNT contents. 
The SEM pictures of the fracture surface of GNP/CNT (50:50) nanocomposites as obtained from various processes including compression molding, filament extrusion, and 3D printing, are shown in Figure 3. SEM figures of compression molded plates (see Figure 3a1-a3) evidence a poor adhesion level between graphene and ABS. The effect of the two processing steps of compounding and extrusion, and the quality of carbon nanotubes and graphene dispersion into the ABS matrix were evaluated from the fracture surface of the GNP/CNT (50:50) nanocomposite filament by SEM analysis, as depicted in Figure 3b1-b3. Some small voids can be observed in Figure 3b1, and, at higher magnification, some microvoids can be evidenced near the filler, as documented by Figure $3 \mathrm{~b} 2$. In particular, the graphene nanoplatelets appear to be oriented mostly perpendicular to the fracture plane of the filament, as depicted in Figure 3b2,b3. Similar to the filament, 3c1-c3 show that, in FFF, the graphene nanoplatelets for GNP/CNT (50:50) HC parts appear to be oriented mostly perpendicular to the fracture plane and, therefore, most likely oriented along the loading direction of dumbbell specimens. It can, therefore, be inferred that, during extrusion, the graphene nanoplatelets are forced to align along the extrusion direction of the filament, and, during the following FFF process, this orientation is then maintained in each single microfilament during the layer deposition.
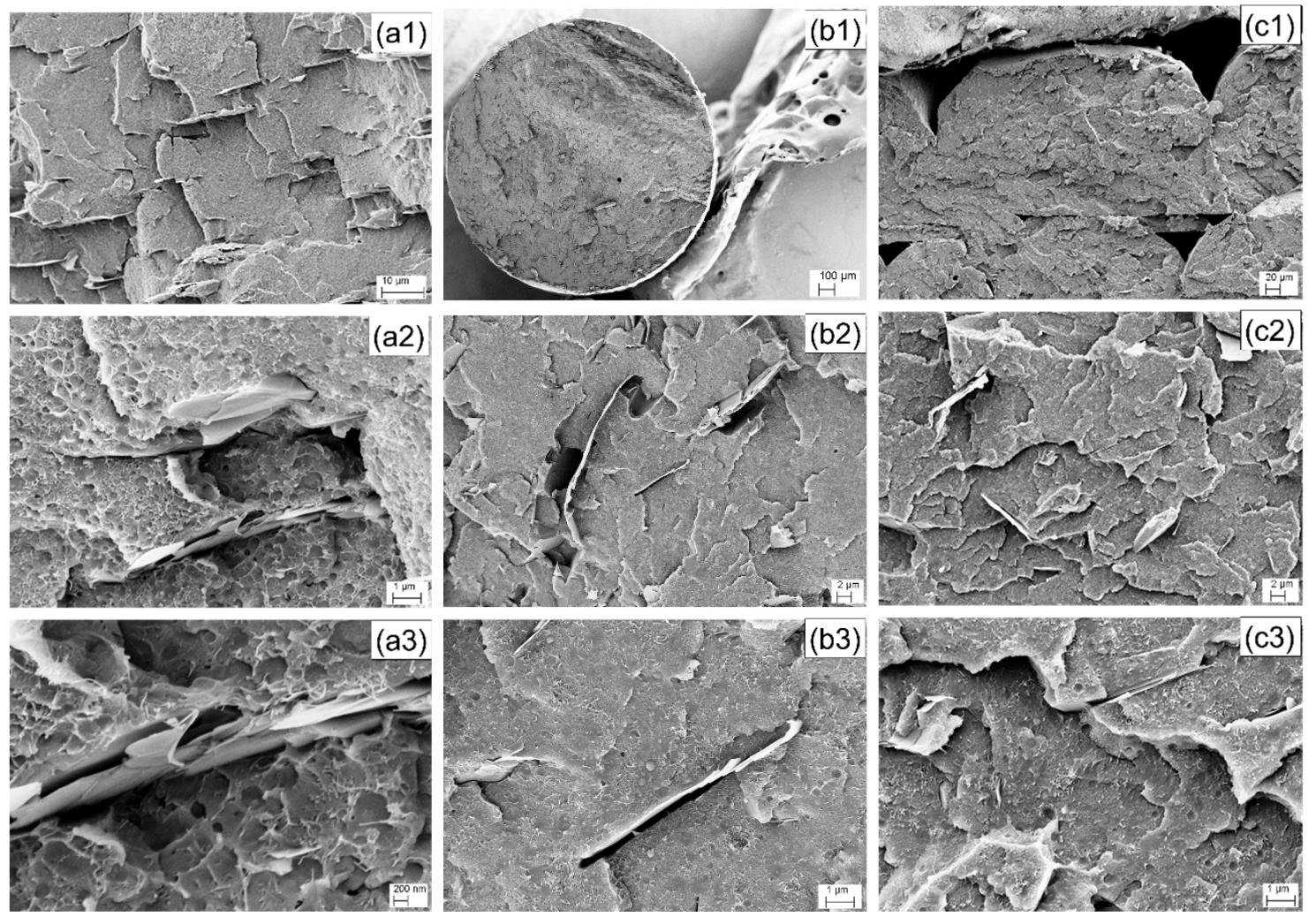

Figure 3. SEM micrographs at increasing magnification of GNP/CNT (50:50) nanocomposites produced by compression molding (a1-a3), filaments (b1-b3), and fused filament fabrication (FFF) horizontal concentric (HC) samples (c1-c3).

\subsection{Tensile Properties}

The tensile properties of hybrid nanocomposites with GNP/CNT at 6 wt.\% obtained from compression molding are presented in Figure 4. The stiffness and strength of GNP/CNT hybrids at various mixture ratios were found superior to those of pure ABS. In particular, the elastic modulus of nanocomposites linearly increased with the amount of GNP content as shown in Figure 4a. For example, single-filler CNT and GNP nanocomposites evidenced elastic modulus improvements of $23 \%$ and $47 \%$, respectively, while the hybrid nanocomposites with a ratio of $50: 50$ exhibited $37 \%$ improvement. On the other hand, the strength of nanocomposites increased with CNT content, as shown in Figure $4 \mathrm{~b}$. 
From Figure $4 c, d$, the strain at break and tensile energy to break of GNP/CNT (0:100) was slightly higher than that of GNP/CNT (100:0) nanocomposites, and the GNP/CNT (50:50) specimen revealed the highest strain at break in comparison with the other nanocomposites. Some studies reported a synergistic effect for hybrid carbon nanotube/graphene nanocomposites at a low concentration of $1 \mathrm{wt} . \%$ nanofiller $[29,30,34]$. On the contrary, our results suggest no evident synergistic effects on tensile modulus and strength, probably due to the higher concentration of nanofiller.

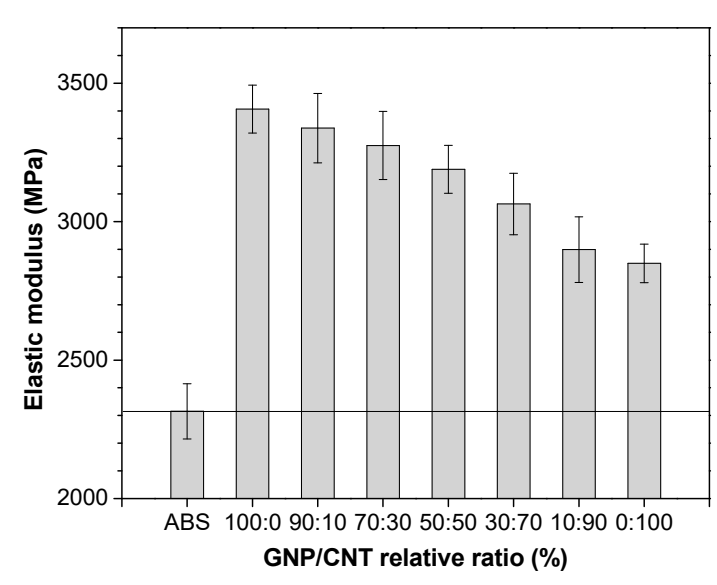

(a)

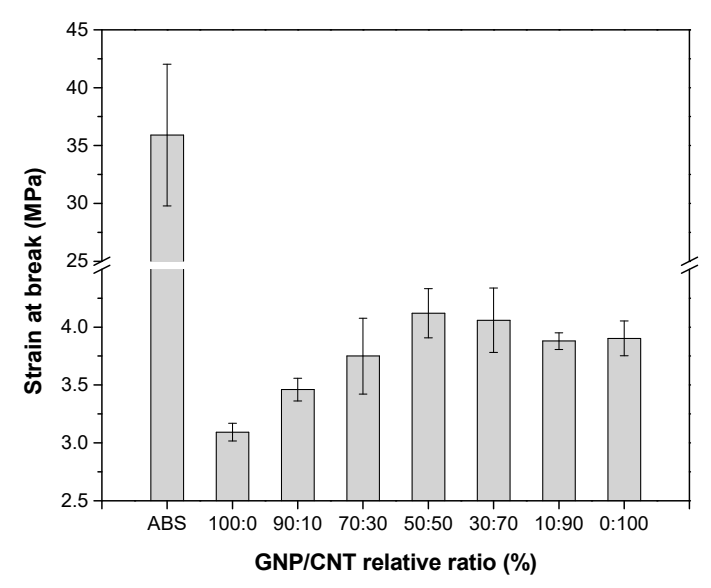

(c)

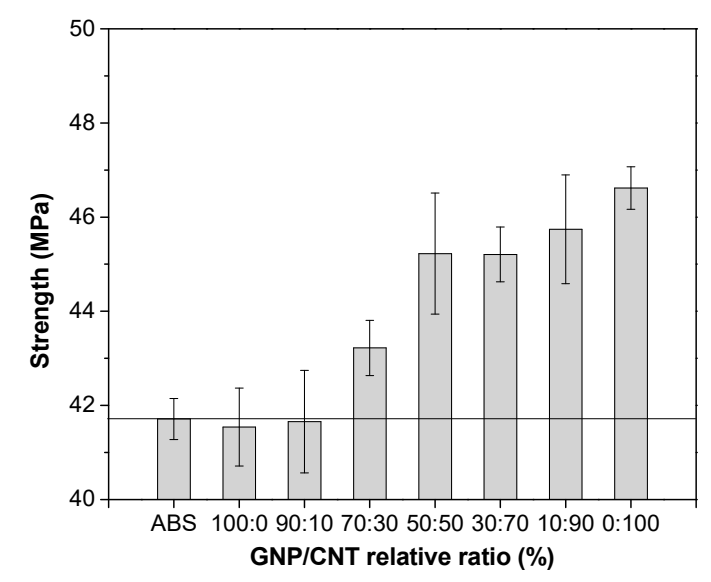

(b)

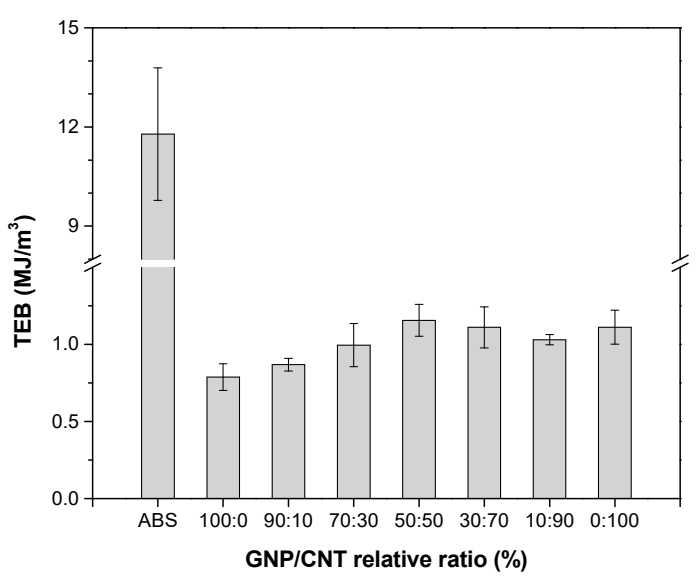

(d)

Figure 4. Tensile properties of ABS and various GNP/CNT hybrid nanocomposites with a total nanofiller amount of 6 wt.\% produced by compression molding: (a) elastic modulus, (b) strength, (c) strain at break, and (d) tensile energy to break (TEB). Representative stress-strain curves are shown in Figure S1a (Supplementary Materials).

The tensile properties of filament and 3D-printed samples including elastic modulus, strength, and strain at break are plotted in Figure 5. The ductility properties of nanocomposite filaments were significantly reduced with respect to neat ABS. In addition, it is worthwhile to note that the elastic modulus of the 50:50 hybrid nanocomposites was higher than that of single CNT nanocomposites, whereas the strength and strain at break of the hybrid composite filament were slightly lower than for pure CNT nanocomposites, and the sample was fractured before the yield point. The tensile properties of 3D-printed (HC and H45) samples showed a similar tendency to the sample produced by compression molding and to the filaments. In particular, Figure 5 evidences that the elastic modulus of hybrid nanocomposites of HC and H45 samples was further increased in comparison with the pure CNT nanocomposites; on the other hand, strength and strain at break of this material (50:50) were slightly reduced with respect to the single CNT nanocomposites. A different behavior was observed 
for FFF samples produced with a PC build orientation, for which the strength and strain at break of the GNP/CNT (50:50) hybrid and (0:100) were significantly reduced compared to neat ABS. Moreover, it should be noted that more brittle behavior of all the PC samples existed, almost independently of the GNP/CNT composition, due to the weakness of bond properties at the cross-sections. In previous work, PLA nanocomposites filled with various GNP/CNT ratios at $6 \mathrm{wt} . \%$ used in 3D printing and processing showed a synergistic effect on mechanical properties. In particular, hybrid nanocomposites evidenced a higher elastic modulus and hardness compared with single GNP and CNT nanocomposites at the same nanofiller concentration, hypothesizing that the long tortuous CNTs prevent GNP aggregation and bridge adjacent graphene, leading to a more efficient network and better reinforcing effects in the matrix [46].

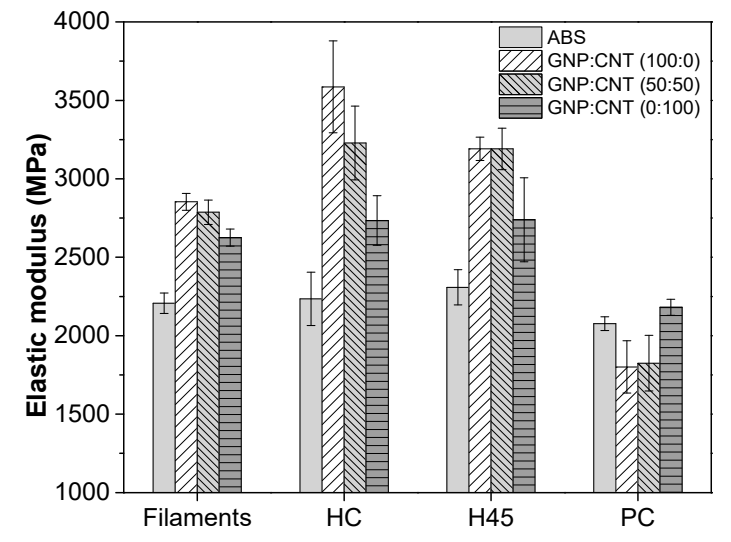

(a)

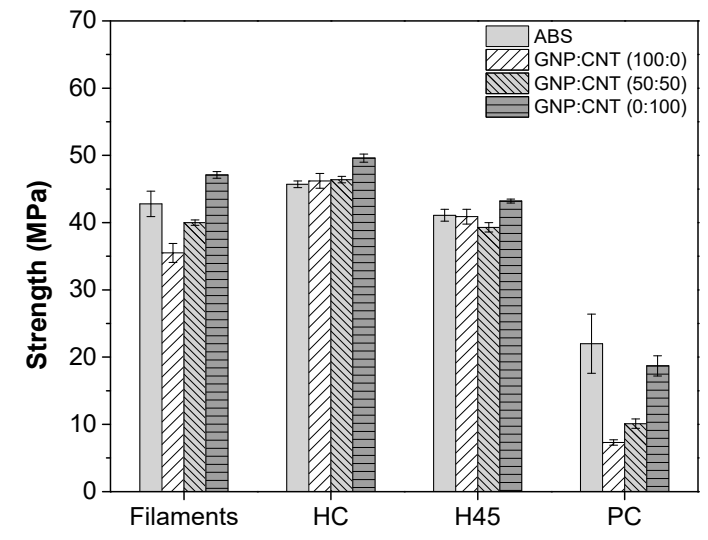

(b)

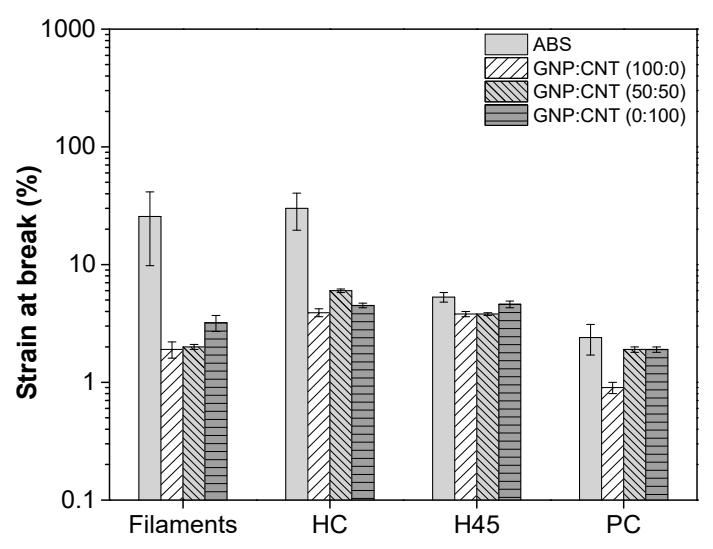

(c)

Figure 5. Quasi-static tensile properties of extruded filaments and FFF samples (HC, horizontal $45^{\circ}$ angle $\mathrm{H} 45$, and perpendicular concentric (PC)) of ABS and its nanocomposite: (a) elastic modulus, (b) strength, and (c) strain at break. Representative stress-strain curves are shown in Figure S1b-e (Supplementary Materials).

\subsection{Electrical Resistivity}

Following the volume electrical measurements, the results of bulk resistivity measurements of the samples containing GNP and CNT nanofillers are reported in Figure 6. From this set of data, it is possible to understand that, upon increasing the CNT relative amount, the resistivity decreased with a nonlinear trend, because of the synergistic effect on electrical resistivity due to the presence of both nanofillers. With a total nanofiller content of $6 \mathrm{wt} . \%$, the nanocomposite required at least a GNP/CNT ratio of 70:30 to have a low electrical resistivity of about $13 \Omega \cdot \mathrm{cm}$ (with an effective CNT content of 
1.8 wt.\%). On the other hand, single-filler nanocomposite samples loaded only with $2 \mathrm{wt.} \%$ of CNT exhibited an electrical resistivity of $30 \Omega \cdot \mathrm{cm}$ [40]; thus, the synergistic effect of GNP in hybrids appears evident. On the other hand, only a small synergistic effect in PLA nanocomposite was reported by Ivanov et al. [31], when combining GNP and CNT at ratios of $3 \mathrm{wt} . \% \mathrm{GNP} / 3 \mathrm{wt} . \% \mathrm{CNT}$ and $1.5 \mathrm{wt} . \%$ GNP $/ 4.5 \mathrm{wt} . \% \mathrm{CNT}$ on electrical conductivity, with no effect on the thermal conductivity.

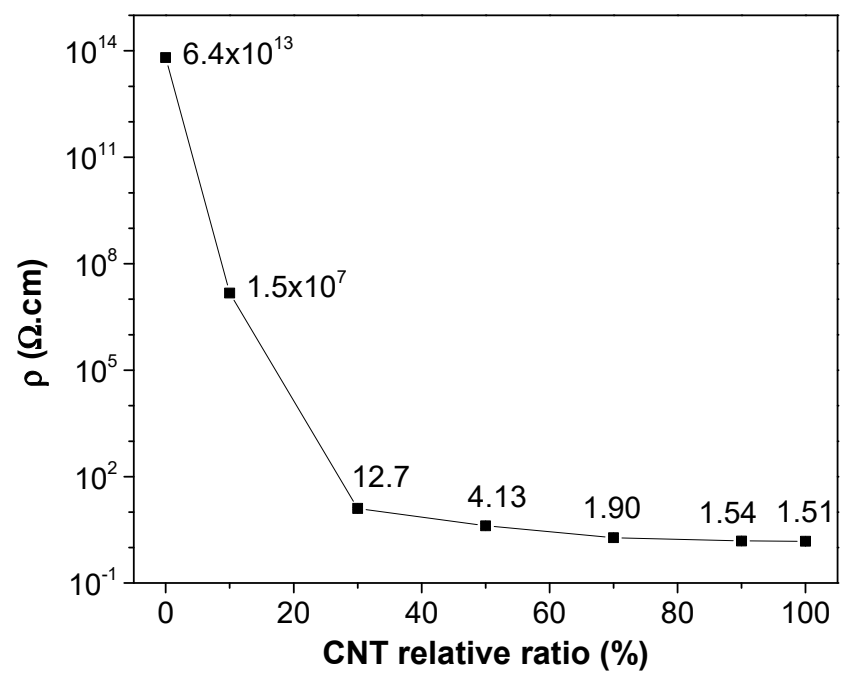

Figure 6. Electrical volume resistivity of $6 \mathrm{wt} . \% \mathrm{GNP} / \mathrm{CNT}$ nanocomposites at different CNT contents produced by compression molding.

The electrical resistivity of single GNP, single CNT, and 50:50 GNP/CNT at 6 wt.\% with different processing is plotted in Figure 7. The nanocomposite filled with only GNP was an insulating material, having a resistivity higher than $10^{13} \Omega \cdot \mathrm{cm}$, independent of the processing. The resistivity of GNP/CNT (50:50) hybrid nanocomposites was $8.45 \Omega \cdot \mathrm{cm}$, slightly higher than that of the nanocomposite with only CNT $(\rho=4.1 \Omega \cdot \mathrm{cm})$, analogously to the correspondent compression molded samples. Moreover, much higher resistivity of GNP/CNT (50:50) hybrid nanocomposites was determined for FFF samples, at about $4.2 \times 10^{5} \Omega \cdot \mathrm{cm}, 1.5 \times 10^{5} \Omega \cdot \mathrm{cm}$, and $1.1 \times 10^{4} \Omega \cdot \mathrm{cm}$ for HC, H45, and PC, respectively. Following these results, nanocomposite FFF plates with $6 \mathrm{wt} . \%$ of CNT were successfully produced for strain monitoring applications [47].

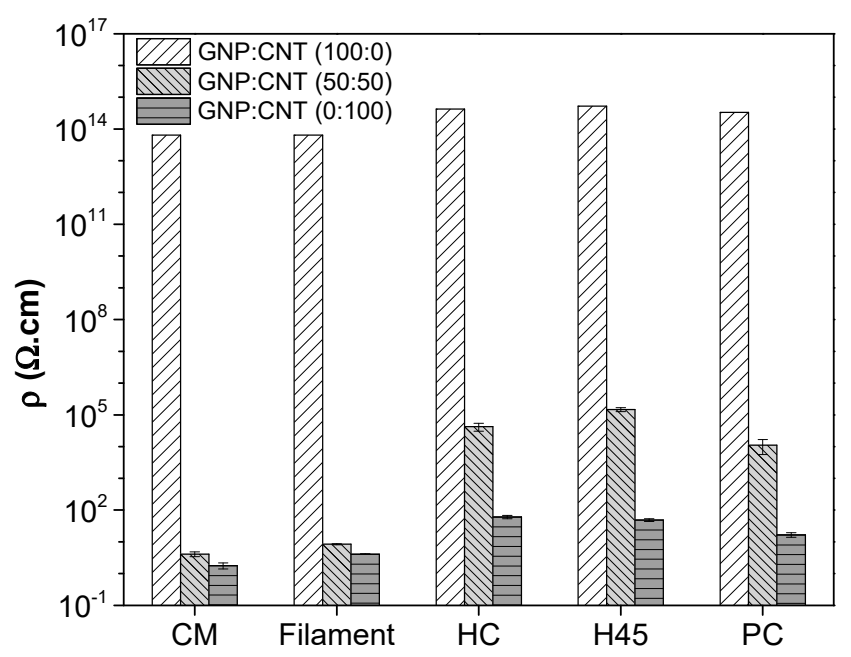

Figure 7. Electrical volume resistivity of GNP, CNT, and GNP/CNT nanocomposites with different processing: compression molding (CM), the filament, and FFF samples (HC, H45, and PC). 


\subsection{Electromagnetic Interference Shielding Effectiveness (EMI SE)}

Electromagnetic interference shielding effectiveness (EMI SE) is determined as the shielding ability of materials from electromagnetic waves. Figure 8 shows the representative plots of EMI SE expressed in decibel $(\mathrm{dB})$ in the frequency range from 8 to $12.4 \mathrm{GHz}$ of the neat $\mathrm{ABS}$ and various single GNP, single CNT, and hybrid (50:50) nanocomposites at $6 \mathrm{wt} . \%$ produced by compression molding. The EMI $\mathrm{SE}$ of all these samples was almost independent of the frequency. The higher shielding effectiveness was achieved in the order of GNP/CNT $(0: 100)>(50: 50)>>(100: 0)>$ ABS samples. These results show a good correlation to electrical volume resistivity. Materials for EMI shielding purposes are generally targeted to have a minimum of $-20 \mathrm{~dB}$ of attenuation, because, at these values of shielding, more than $99 \%$ of the incident wave is attenuated, ensuring that electronic equipment does not generate or is not affected by electromagnetic interference $[48,49]$. Therefore, it is interesting to note that samples containing $6 \mathrm{wt}$ \% of CNT and hybrid (50:50) nanofillers could reach EMI SE levels of $-46 \mathrm{~dB}$ and $-31.7 \mathrm{~dB}$, respectively, which meet the EMI SE levels required for commercial applications.

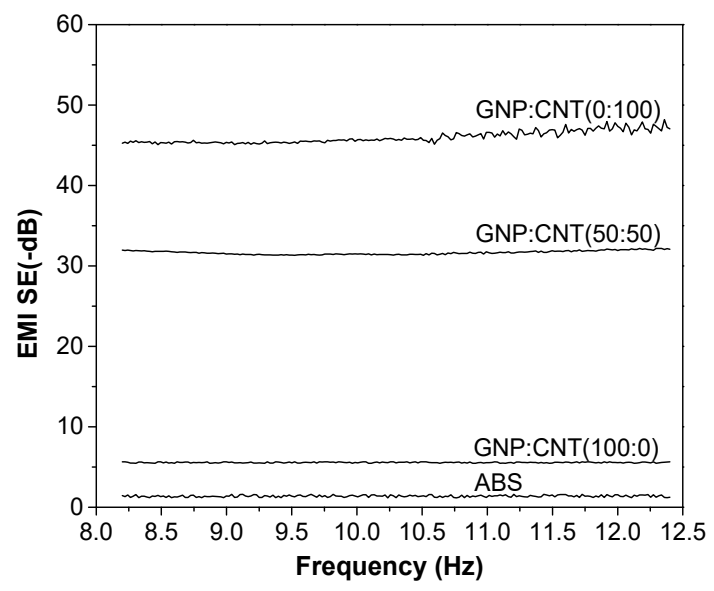

(a)

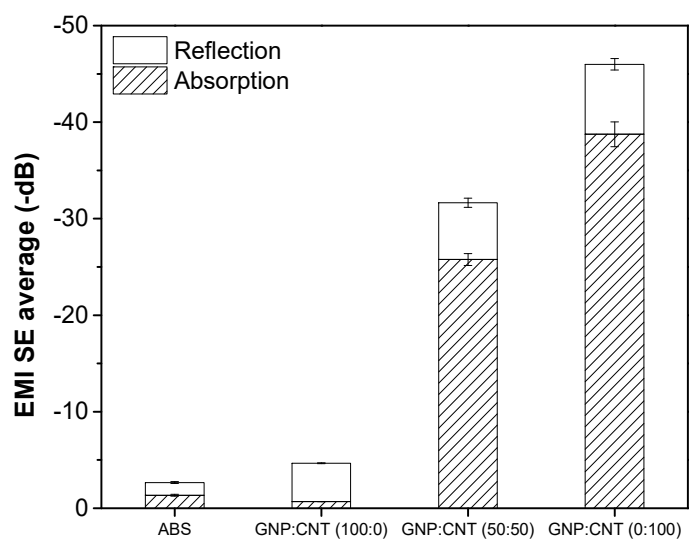

(b)

Figure 8. Electromagnetic interference shielding effectiveness (EMI SE0 of neat ABS, as well as single and hybrid nanocomposites, produced by compression molding with a total filler content of $6 \mathrm{wt}$. $\%$ : (a) representative curves and (b) influence of absorption $\mathrm{SE}_{\mathrm{A}}$ and reflection $\mathrm{SE}_{\mathrm{R}}$ mechanisms.

The average values of reflection and absorption contributing in the frequency range from 8.2-12.4 GHz are compared in Figure 8b. It is evident that the shielding absorption contribution $\mathrm{SE}_{\mathrm{A}}$ of composites containing carbon nanotubes was higher than that of the reflection, i.e., $\mathrm{SE}_{\mathrm{A}}>\mathrm{SE}_{\mathrm{R}}$. On the other hand, the dominant shielding mechanism for ABS/graphene composites was reflection, due to the platelet-shaped GNP that provided a higher surface area for interaction with the electromagnetic waves.

Figure 9a-c show the representative plots of EMI SE of the neat ABS and various single GNP, single $\mathrm{CNT}$, and hybrid (50:50) nanocomposites at $6 \mathrm{wt} . \%$ produced by FFF at different build orientations in the frequency range from 8 to $12.4 \mathrm{GHz}$. The nanocomposites with CNT show a slight influence of the shielding effectiveness on the frequency in the X-band. Accordingly, EMI SE responses were found to be a function of both the type of filler and the build orientation of the specimens. The shielding effectiveness decreased in the following order: GNP/CNT $(0: 100)>(50: 50)>>(100: 0)>A B S$, independently of the build orientation of the specimens. These results show the same tendency as the electrical volume resistivity. Regarding the build orientation, it can be observed that the specimens prepared along the PC build orientation exhibited a better attenuation (of the electromagnetic radiation). For instance, the total EMI SE of the carbon nanotube-based composite built along PC was around $-25.3 \mathrm{~dB}$, whereas the same composite built along $\mathrm{HC}$ and $\mathrm{H} 45$ exhibited attenuation of -14.4 and $-15.3 \mathrm{~dB}$, respectively. Similar differences can also be observed for hybrid composites, with EMI SE values of $-16.1,-11.3$, and $-12.7 \mathrm{~dB}$ for PC, HC, and H45, respectively. On the other hand, ABS/GNP composites, 
directly dependent on their high level of resistivity, revealed poor values of attenuation, near $-4.5 \mathrm{~dB}$, independent of the build direction.

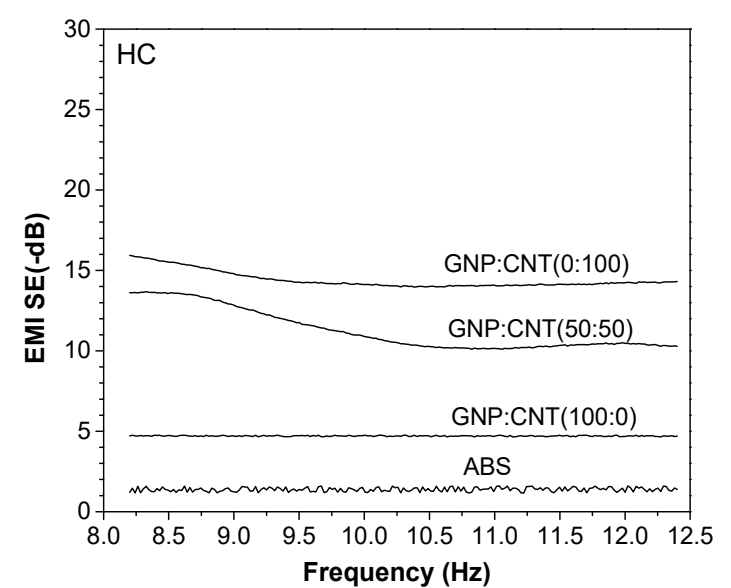

(a)

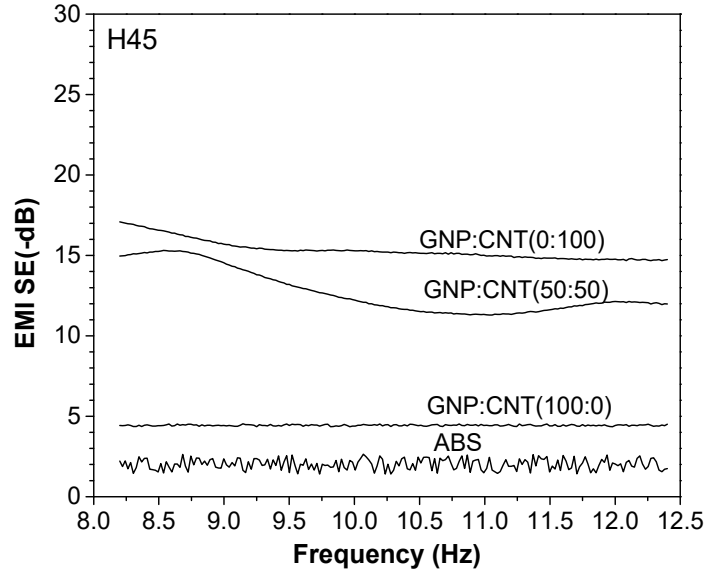

(b)

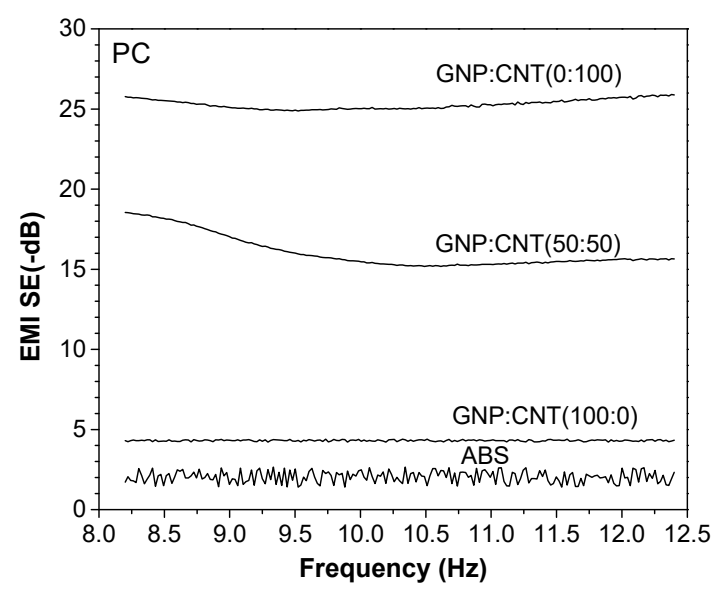

(c)

Figure 9. Representative curves of EMI SE of hybrid nanocomposite samples produced by FFF three-dimensional (3D) printing: (a) HC, (b) H45, and (c) PC.

The average values of reflection and absorption contributions in the frequency range of 8.2-12.4 GHz are reported in Figure 10. The results of FFF samples regardless of the build orientation were analogous to those of compression molded samples. In fact, the shielding absorption contribution in nanocomposites containing carbon nanotubes was higher than that of the reflection, whereas the dominant shielding mechanism was reflection for ABS/graphene composites.

The relationship between the decrease in resistivity and the correspondent effect of increasing the magnetic shield after the addition of carbonaceous fillers is summarized in Figure 11. The better performance of CNT and GNP/CNT hybrid nanocomposites, with reduced resistivity and the correspondent higher EMI SE, is quite evident. The samples produced by compression molding evidence better results than those obtained from 3D printing. 

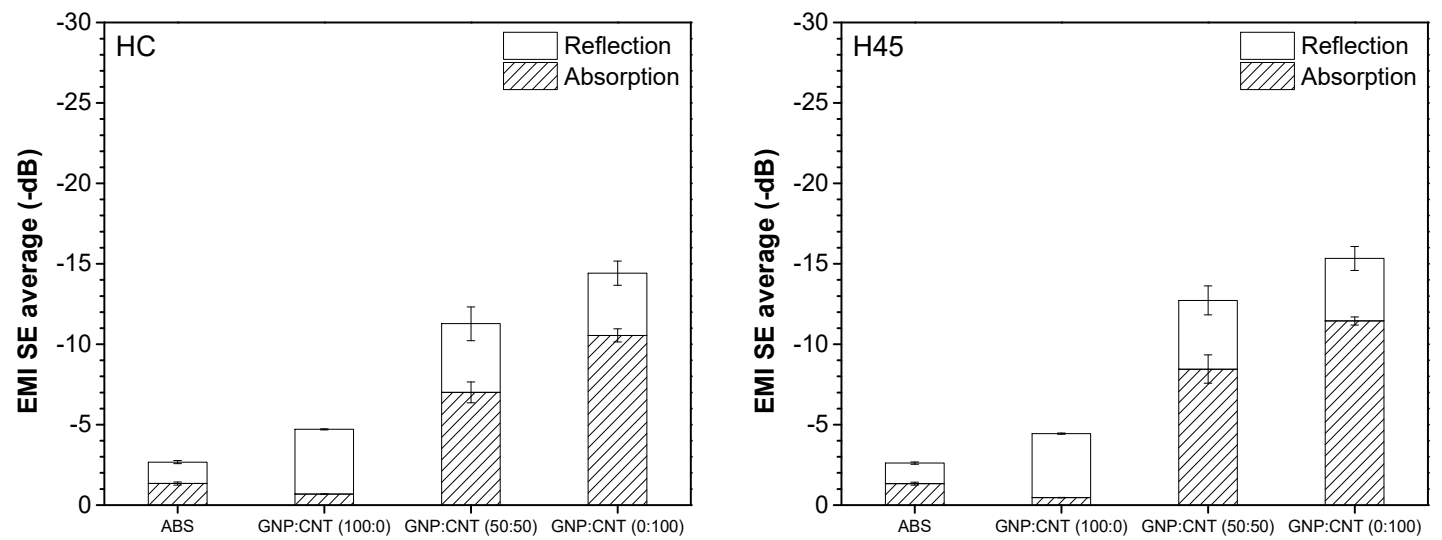

(a)

(b)

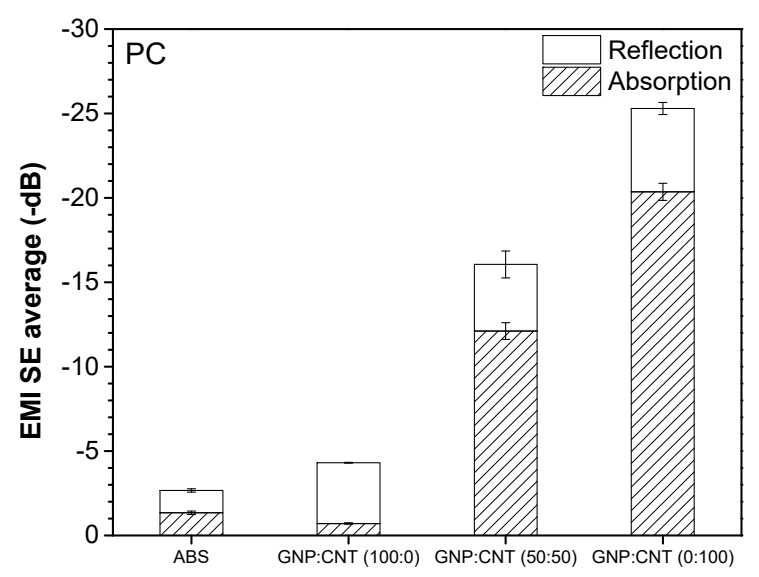

(c)

Figure 10. Influence of absorption and reflection mechanisms on the EMI SE of hybrid nanocomposites from FFF 3D printing: (a) HC, (b) H45, and (c) PC.

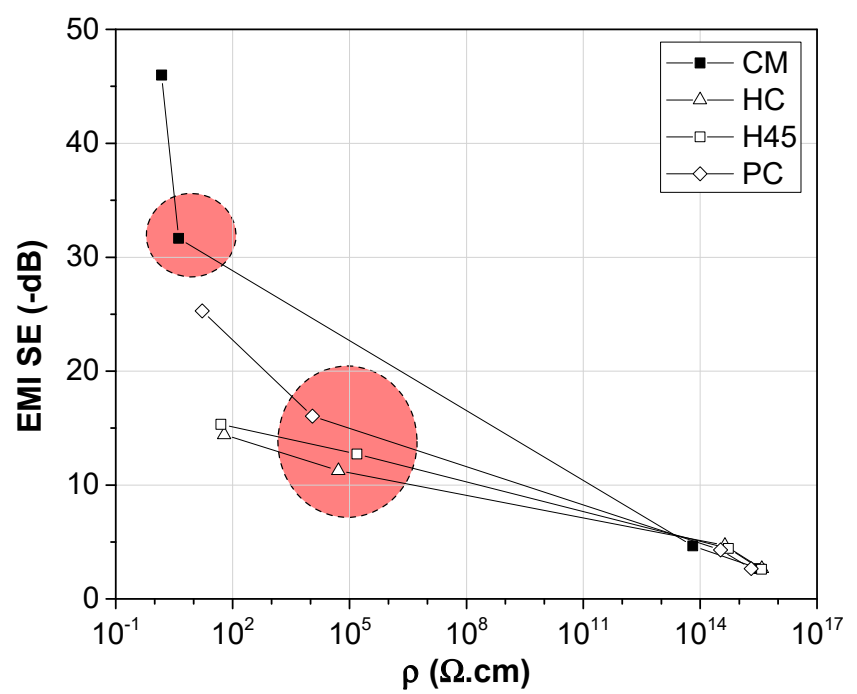

Figure 11. Electromagnetic shielding vs. resistivity of neat ABS, and different GNP, CNT, and hybrid nanocomposites (red circles) at $6 \mathrm{wt}$.\% produced by compression molding (CM) or by 3D printing. 


\subsection{Comparison of the Results to Literature Data}

This paragraph summarizes the main results of these studied GNP/CNT nanocomposites, and compares their values with some relevant literature data. Figure 12 shows the processability (melt flow index), resistivity, electromagnetic shielding, and tensile properties of graphene, carbon nanotube, and hybrid nanocomposites at $6 \mathrm{wt}$.\% from compression molding. It is interesting to observe that the GNP/CNT (50:50) samples were a good compromise between the decrease in processability and the increase in mechanical, electrical resistivity, and electromagnetic properties. Analogous pictures were found for FFF samples produced with different build orientation, as shown in Figure S2 (Supplementary Materials). In particular, PC samples exhibited better conductive and EMI SE properties with respect to $\mathrm{HC}$ and $\mathrm{H} 45$ samples, but lower mechanical properties.

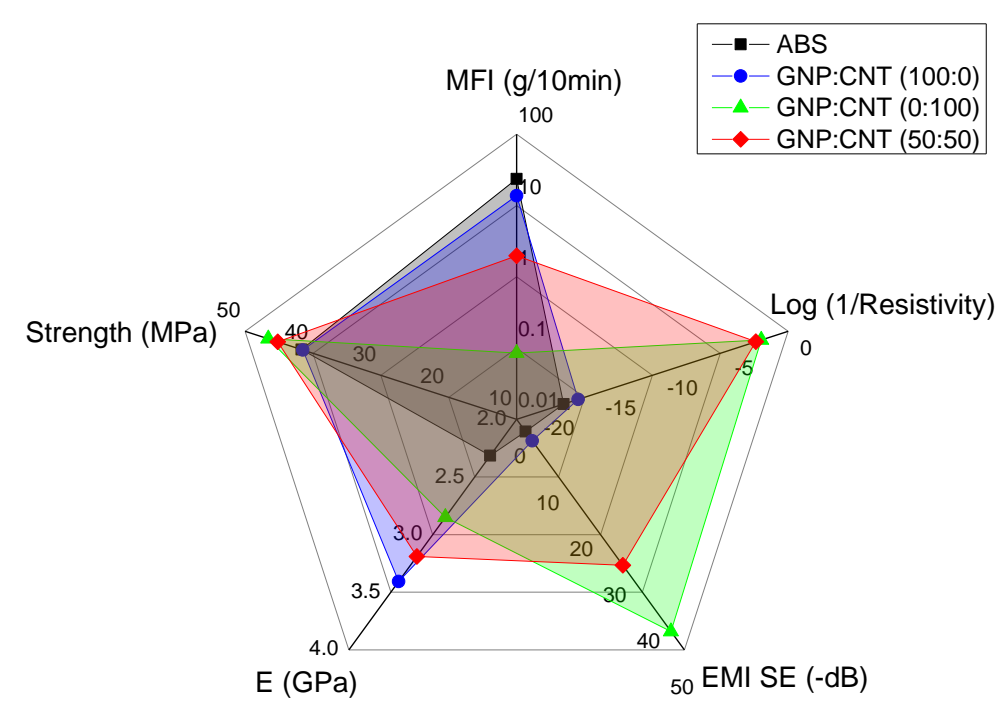

Figure 12. Comparative plot of compression molded nanocomposite at $6 \mathrm{wt}$ \%. Processability (MFI), resistivity, electromagnetic shielding (EMI SE), and tensile properties of graphene, carbon nanotube, and 50:50 hybrid nanocomposites with respect to ABS matrix. Spider plots of FFF samples are reported in Figure S3 (Supplementary Materials) for comparison.

The summary of the main properties of GNP/CNT hybrid nanocomposites at $6 \mathrm{wt}$ \% is also reported in Table S1 (Supplementary Materials). For the purpose of quantitative evaluation of the effect of GNP/CNT relative ratio, we can determine comparative parameters that take into consideration some specific properties important for applications. In particular, the properties of nanocomposites such as the stiffness, the processability, and the electrical resistivity should be taken into account. Hence, an interesting merit parameter $P_{E, M, \rho}$ was recently defined [40]. From Figure S2 (Supplementary Materials), the $P_{E, M, \rho}$ parameter assumes the highest value at 50:50 and 70:30 GNP/CNT relative ratios.

A final comparison of properties of the thermoplastic nanocomposites presented in this study and some correspondent engineering polymers containing similar types of carbon nanoparticles is detailed in Table 3. The processing techniques and the comparative values could be useful for ranking the various nanocomposites in terms of dependence on the required applications. The addition of carbonaceous nanofillers is reported to provide beneficial effects in reinforcement and in electrical performances of the various thermoplastics, such as ABS, ABS/polycarbonate (PC), PLA, polybutylene terephthalate (PBT), polyamide 12 (PA12), PHA (polyhydroxy alkanoate), and PEEK. CNT provides a significant increase in electrical and electromagnetic shielding properties, much higher than GNP with a similar amount of filler. For instance, on ABS/CNT composites with 5 wt.\% of filler content, electromagnetic shielding of $-38.0 \mathrm{~dB}$ at $8.0-12.0 \mathrm{GHz}$ and electrical conductivity values of and $2.0 \times 10^{-3} \mathrm{~S} / \mathrm{cm}$ were reached [50]. An EMI SE value of $-60 \mathrm{~dB}$ at $8.0-12.0 \mathrm{GHz}$ and conductivity of $0.166 \mathrm{~S} / \mathrm{cm}$ for ABS composites were achieved by adding $15 \mathrm{wt}$.\% of graphene nanoplatelets [51]. 
The properties of the products from FFF show sometimes higher properties than those produced by compression molding. Spinelli et al. [33] produced PLA nanocomposites containing $12 \mathrm{wt} . \%$ of GNP, $\mathrm{CNT}$, and their mixing for 3D printing. The 3D-printed parts exhibited improved electrical conductivity up to $4.54 \mathrm{~S} / \mathrm{m}, 6.57 \mathrm{~S} / \mathrm{m}$, and $0.95 \mathrm{~S} / \mathrm{m}$ respectively. EMI SE values in the frequency range 26-37 GHz of samples also increased from $0.20 \mathrm{~dB}$ of unfilled PLA up to $-13.4 \mathrm{~dB}$ for GNP/CNT (1:1) nanocomposites. However, taking into consideration the $\mathrm{T}_{\mathrm{g}}$ of the PLA matrix, a specific application temperature is in the range $20-50{ }^{\circ} \mathrm{C}$, which is relatively lower than that of $\mathrm{ABS}$ (up to $80-90^{\circ} \mathrm{C}$ ). Another study reported ABS-based nanocomposites with the presence of hybrid carbon nanotube/carbon black (1:1) of 3 wt.\% fillers from 3D printing with an EMI SE value of $-8 \mathrm{~dB}$ in the range 8.2-12.4 GHz [22]. For high-performance thermoplastics, 3D-printed PEEK filled with $7 \mathrm{wt} . \%$ of a GNP/CNT (4:3) mixture demonstrated electrical conductivity of about $1.0 \times 10^{-6} \mathrm{~S} / \mathrm{cm}$, but no electromagnetic shielding behavior was reported [35]. In our work, the ABS matrix was incorporated at $6 \mathrm{wt} . \%$ of GNP, CNT, and GNP/CNT (50:50) composites for 3D printing with EMI SE values in the frequency band 8.2-12.4 GHz of -4.4, -15.3 , and $-12.7 \mathrm{~dB}$, respectively. 
Table 3. Comparison of selected properties of ABS nanocomposites studied in this research with respect to other carbon-based engineering polymers.

\begin{tabular}{|c|c|c|c|c|c|c|c|c|c|}
\hline \multirow{2}{*}{ Matrix } & \multirow{2}{*}{ Type of Nanofiller } & \multirow{2}{*}{$\begin{array}{c}\text { Nanofiller } \\
\text { Content }\end{array}$} & \multirow{2}{*}{ Process Technique * } & \multirow{2}{*}{ Modulus ** } & \multirow{2}{*}{ Strength $* *$} & \multirow{2}{*}{ Conductivity $(\mathrm{S} / \mathrm{cm})$} & \multicolumn{2}{|c|}{ EMI SE } & \multirow{2}{*}{ Reference } \\
\hline & & & & & & & Thickness & $(-d B)$ & \\
\hline & Graphene & & & & & & & & \\
\hline ABS & GNP nanosheet & 0.13 vol. $\%$ & $\mathrm{SM} / \mathrm{CM}$ & - & - & $1.0 \times 10^{-3}$ & - & - & [52] \\
\hline ABS & C18-graphene & 1 wt.\% & $\mathrm{SM} / \mathrm{SC}$ & $+18 \%$ & $+38 \%$ & - & - & - & [53] \\
\hline ABS & GNP nanosheet & 2 wt. $\%$ & $\mathrm{SM} / \mathrm{CM}$ & $+48 \%$ & $+41 \%$ & - & - & - & [54] \\
\hline ABS & Graphite & 4.9 vol. $\%$ & $\mathrm{MM} / \mathrm{CM}$ & - & - & $2.0 \times 10^{-1}$ & - & & [55] \\
\hline ABS & GO & $5.6 \mathrm{wt} . \%$ & $\mathrm{SM} / 3 \mathrm{DP}$ & - & - & $1.1 \times 10^{-5}$ & - & - & [56] \\
\hline ABS & Graphite & $15 \mathrm{wt} . \%$ & $\mathrm{MM} / \mathrm{CM}$ & - & - & $1.6 \times 10^{-1}$ & $3 \mathrm{~mm}$ & 60 at $8.0-12.0 \mathrm{GHz}$ & [51] \\
\hline ABS & Graphite & 40 vol. $\%$ & MM/IM & $+96 \%$ & $-19 \%$ & - & - & - & [57] \\
\hline $\mathrm{ABS} / \mathrm{PC}$ & GNP & $3 \mathrm{wt} . \%$ & $\mathrm{MM} / \mathrm{IM}$ & $+30 \%$ & $+15 \%$ & - & - & - & [58] \\
\hline PLA & r-GO & $6 \mathrm{wt} . \%$ & $\mathrm{MM} / 3 \mathrm{DP}$ & $+36 \%$ & $+74 \%$ & $4.7 \times 10^{0}$ & & - & [59] \\
\hline PLA & GNP & $6 \mathrm{wt} . \%$ & $\mathrm{MM} / 3 \mathrm{DP}$ & - & - & $8.4 \times 10^{-5}$ & - & - & [31] \\
\hline PLA & GNP & 12 wt. $\%$ & $\mathrm{MM} / 3 \mathrm{DP}$ & - & - & $6.3 \times 10^{-2}$ & $10 \mathrm{~mm}$ & 10.2 at $30 \mathrm{GHz}$ & [33] \\
\hline РBT & GNP & 8.4 vol. $\%$ & SM/3DP & - & - & $4.0 \times 10^{-2}$ & - & - & [60] \\
\hline \multirow[t]{2}{*}{ PA12 } & Graphene & 5 wt. $\%$ & $\mathrm{MM} / \mathrm{CM}$ & - & - & $2.0 \times 10^{-2}$ & - & - & [61] \\
\hline & Carbon Nanotubes & & & & & & & & \\
\hline ABS & $\mathrm{CNT}$ & 3 wt. $\%$ & $\mathrm{MM} / \mathrm{CM}$ & - & - & $10^{-2}$ & $2 \mathrm{~mm}$ & 10 at $8.2-12.4 \mathrm{GHz}$ & [22] \\
\hline ABS & CNT & 5 wt. $\%$ & Solid mixing/CM & - & - & $2.0 \times 10^{-3}$ & $2.8 \mathrm{~mm}$ & 38.0 at $8-12 \mathrm{GHz}$ & [50] \\
\hline ABS & CNT & 6.1 vol. $\%$ & $\mathrm{SM} / \mathrm{CM}$ & - & - & $1.0 \times 10^{0}$ & - & - & [62] \\
\hline PLA & $\mathrm{CNT}$ & 12 wt. $\%$ & $\mathrm{MM} / 3 \mathrm{DP}$ & - & - & $4.5 \times 10^{-2}$ & $10 \mathrm{~mm}$ & 10.2 at $30 \mathrm{GHz}$ & [33] \\
\hline PLA & $\mathrm{CNT}$ & 6 wt. $\%$ & $\mathrm{MM} / 3 \mathrm{DP}$ & - & - & $2.1 \times 10^{-4}$ & - & - & [31] \\
\hline PHAs & f-MWCNT & $1 \mathrm{wt} . \%$ & MM/extrusion & $+33 \%$ & $+102 \%$ & $1.0 \times 10^{-7}$ & - & - & [63] \\
\hline PA12 & $\mathrm{CNT}$ & $5 \mathrm{wt} . \%$ & MM/CM & - & - & $1.4 \times 10^{-1}$ & - & - & [61] \\
\hline \multirow[t]{2}{*}{ PBT } & $\mathrm{CNT}$ & 3.5 vol. $\%$ & $\mathrm{SM} / 3 \mathrm{DP}$ & - & - & $2.5 \times 10^{-1}$ & - & - & [60] \\
\hline & Carbon Black & & & & & & & & \\
\hline ABS & СВ & $3 \mathrm{wt} . \%$ & $\mathrm{MM} / \mathrm{CM}$ & - & - & $10^{-7}$ & $2 \mathrm{~mm}$ & 4 at $8.2-12.4 \mathrm{GHz}$ & [22] \\
\hline \multirow[t]{2}{*}{ ABS } & СВ & 15 wt. $\%$ & $\mathrm{MM} / 3 \mathrm{DP}$ & - & - & $3.4 \times 10^{-4}$ & - & - & [64] \\
\hline & Hybrids & & & & & & & & \\
\hline ABS & $\mathrm{CB} / \mathrm{CNT}$ & 3 wt. $\%$ & $\mathrm{MM} / 3 \mathrm{DP}$ & - & - & $10^{-3}$ & $2 \mathrm{~mm}$ & 8 at $8.2-12.4 \mathrm{GHz}$ & [22] \\
\hline PLA & GNP/CNT & $12 \mathrm{wt} . \%$ & $\mathrm{MM} / 3 \mathrm{DP}$ & $\sim 20 \%$ & - & - & - & - & [46] \\
\hline PLA & GNP/CNT & $12 \mathrm{wt} . \%$ & $\mathrm{MM} / 3 \mathrm{DP}$ & $46 \%$ & $-21 \%$ & $2.2 \times 10^{-3}$ & - & - & [65] \\
\hline PLA & GNP/CNT & 6 wt. $\%$ & MM/3DP & - & - & $5.9 \times 10^{-2}$ & - & - & [31] \\
\hline PLA & GNP/CNT & $12 \mathrm{wt} . \%$ & $\mathrm{MM} / 3 \mathrm{DP}$ & - & - & $9.5 \times 10^{-3}$ & $10 \mathrm{~mm}$ & 13.5 at $30 \mathrm{GHz}$ & [33] \\
\hline PEEK & GNP/CNT & 7 wt. $\%$ & $\mathrm{MM} / 3 \mathrm{DP}$ & $\sim+11 \%$ & $\sim+2 \%$ & $\sim 1.0 \times 10^{-6}$ & - & - & [35] \\
\hline ABS & - & 0 & $\mathrm{MM} / 3 \mathrm{DP}$ & $2308 \mathrm{MPa}$ & 41.1 MPa & $1.6 \times 10^{-16}$ & $2 \mathrm{~mm}$ & 2.7 at $8.2-12.4 \mathrm{GHz}$ & This study \\
\hline ABS & GNP & $6 \mathrm{wt} . \%$ & $\mathrm{MM} / 3 \mathrm{DP}$ & $+38 \%$ & $-1 \%$ & $1.9 \times 10^{-15}$ & $2 \mathrm{~mm}$ & 4.4 at $8.2-12.4 \mathrm{GHz}$ & This study \\
\hline ABS & CNT & 6 wt. $\%$ & $\mathrm{MM} / 3 \mathrm{DP}$ & $+19 \%$ & $+5 \%$ & $6.8 \times 10^{-6}$ & $2 \mathrm{~mm}$ & 15.3 at $8.2-12.4 \mathrm{GHz}$ & This study \\
\hline ABS & GNP/CNT & 6 wt. $\%$ & $\mathrm{MM} / 3 \mathrm{DP}$ & $+38 \%$ & $-4 \%$ & $2.0 \times 10^{-2}$ & $2 \mathrm{~mm}$ & 12.7 at $8.2-12.4 \mathrm{GHz}$ & This study \\
\hline
\end{tabular}

* MM is melt mixing; SM is solution mixing; CM is compression molding; IM is injection molding; SC is solution casting; 3DP is three-dimensional printing. ${ }^{* *}$ Relative percentage variation with respect to the neat polymeric matrix. GO: graphene oxide; r-GO: reduced graphene oxide; f-MWCNT: functionalized multi-walled carbon nanotubes; PC: polycarbonate; PLA: polylactide;PBT: polybutylene terephthalate; PA12: polyamide 12; PHAs: polyhydroxy alkanoate); PEEK: polyether ether ketone. 


\section{Conclusions}

The objective of the present work was to develop electrically conductive carbon-based thermoplastic materials, with good mechanical properties, suitable for 3D printing by fused deposition modeling. The manufacture of the nanocomposites with a total amont of $6 \mathrm{wt} . \%$ of GNP/CNT nanofiller was performed by direct melt compounding, and various samples with different compositions were produced either by compression molding or by filament extrusion. A higher CNT content led to lower resistivity and higher electromagnetic shielding, but lower melt flow index. The GNP/CNT hybrid nanocomposites showed values of elastic modulus, strength, electrical resistivity, and processability intermediate to those manifested by nanocomposites filled with either GNP or CNT. Substitution of GNP by CNT provided a positive effect on the electrical resistivity and an improvement of EMI SE, but a certain reduction of modulus and flow properties. The electrical conductive filament $(\rho=8.5 \Omega \cdot \mathrm{cm})$ and FFF parts were achieved after the addition of GNP/CNT content. However, their resistivity increased after the 3D printing process. GNP/CNT hybrid composition of $6 \mathrm{wt}$ \% carbonaceous nanocomposites showed a good compromise between processability and enhancement of properties (mainly mechanical and electrical properties). In agreement with electrical resistivity, EMI SE of $6 \mathrm{wt} . \% \mathrm{ABS} / \mathrm{CNT}$ and 50:50 hybrid ABS nanocomposites resulted as $-46 \mathrm{~dB}$ and $-31.7 \mathrm{~dB}$ for plate samples. The EMI SE of FFF parts was about $-14 \mathrm{~dB}$ for HC and H45 build orientations and $-25 \mathrm{~dB}$ for the PC build orientation for ABS/CNT nanocomposites. Similar EMI SE values of FFF hybrid nanocomposites were observed, almost independent of the building process, of about $-12 \mathrm{~dB}$ for $\mathrm{HC}$ and $\mathrm{H} 45$, and $-16 \mathrm{~dB}$ for PC samples.

Supplementary Materials: The following are available online at http://www.mdpi.com/2073-4360/12/1/101/s1: Figure S1. Representative stress-strain curves of neat ABS, and GNP/CNT (100:0), GNP/CNT (50:50), and GNP/CNT (0:100) nanocomposites: (a) compression molded samples, (b) filaments, (c) HC, (d) H45, and (e) PC samples; Figure S2. The merit parameter P from Equation (S1) combines and compares the effects of elastic modulus, melt flow index $\left(220^{\circ} \mathrm{C}\right)$, and resistivity of nanocomposites with CNT/GNP $6 \mathrm{wt} . \%$ as a function of relative ratio of CNT (from Table S1); Figure S3. Spider plots of FFF samples with relative comparison of processability (MFI), resistivity, electromagnetic shielding (EMI SE), and tensile properties of graphene, carbon nanotube, and 50:50 hybrid nanocomposites with respect to the ABS matrix: (a) HC, (b) H45, and (c) PC; Table S1: The summary of properties of GNP/CNT hybrid nanocomposites.

Author Contributions: S.D., A.P., and L.F. conceptualized and designed the experiments; S.D. performed the experiments; L.G.E. performed EMI SE experiments and data analysis; S.D., A.P., and L.F. analyzed the data and wrote the paper. All authors have read and agreed to the published version of the manuscript.

Acknowledgments: The authors wish to thank Versalis S.p.A. (Mantova, Italy) for donating the ABS pellet polymer for this work. The authors are also thankful to Sharebot S.r.l. (Nibionno, LC, Italy) for providing the prototype of the HT Next Generation desktop 3D printer. One author (Dul. S) is grateful to the AREAS+ EU Project of Erasmus Mundus Action 2 Program for financial support.

Conflicts of Interest: The authors declare no conflicts of interest.

\section{References}

1. Mohan, V.B.; Lau, K.-T.; Hui, D.; Bhattacharyya, D. Graphene-based materials and their composites: A review on production, applications and product limitations. Compos. Part B Eng. 2018, 142, 200-220. [CrossRef]

2. Chizari, K.; Arjmand, M.; Liu, Z.; Sundararaj, U.; Therriault, D. Three-dimensional printing of highly conductive polymer nanocomposites for emi shielding applications. Mater. Today Commun. 2017, 11, 112-118. [CrossRef]

3. Mittal, G.; Dhand, V.; Rhee, K.Y.; Park, S.-J.; Lee, W.R. A review on carbon nanotubes and graphene as fillers in reinforced polymer nanocomposites. J. Ind. Eng. Chem. 2015, 21, 11-25. [CrossRef]

4. Park, S.J.; Seo, M.K. Carbon fiber-reinforced polymer composites: Preparation, properties, and applications. In Polym. Composites; Thomas, P.D.S., Kuruvilla, P.D.J., Malhotra, D.S.K., Goda, P.K., Sreekala, D.M.S., Eds.; Wiley-VCH Verlag GmbH \& Co. KGaA: Weinheim, Germany, 2012; Volume 1.

5. Chen, J.; Liu, B.; Gao, X.; Xu, D. A review of the interfacial characteristics of polymer nanocomposites containing carbon nanotubes. RSC Adv. 2018, 8, 28048-28085. [CrossRef] 
6. Soares da Silva, J.P.; Soares, B.G.; Livi, S.; Barra, G.M.O. Phosphonium-based ionic liquid as dispersing agent for mwcnt in melt-mixing polystyrene blends: Rheology, electrical properties and emi shielding effectiveness. Mater. Chem. Phys. 2017, 189, 162-168. [CrossRef]

7. Bagotia, N.; Choudhary, V.; Sharma, D.K. Synergistic effect of graphene/multiwalled carbon nanotube hybrid fillers on mechanical, electrical and emi shielding properties of polycarbonate/ethylene methyl acrylate nanocomposites. Compos. Part B Eng. 2019, 159, 378-388. [CrossRef]

8. MacGregor, D.G.; Slovic, P.; Morgan, M.G. Perception of risks from electromagnetic fields: A psychometric evaluation of a risk-communication approach. Risk Anal. 1994, 14, 815-828. [CrossRef]

9. Chung, D.D.L. Electromagnetic interference shielding effectiveness of carbon materials. Carbon 2001, 39, 279-285. [CrossRef]

10. Thomassin, J.-M.; Jérôme, C.; Pardoen, T.; Bailly, C.; Huynen, I.; Detrembleur, C. Polymer/carbon based composites as electromagnetic interference (emi) shielding materials. Mater. Sci. Eng. R Rep. 2013, 74, 211-232. [CrossRef]

11. Pawar, S.P.; Biswas, S.; Kar, G.P.; Bose, S. High frequency millimetre wave absorbers derived from polymeric nanocomposites. Polymer 2016, 84, 398-419. [CrossRef]

12. Pang, H.; Xu, L.; Yan, D.-X.; Li, Z.-M. Conductive polymer composites with segregated structures. Prog. Polym. Sci. 2014, 39, 1908-1933. [CrossRef]

13. Al-Saleh, M.H.; Sundararaj, U. A review of vapor grown carbon nanofiber/polymer conductive composites. Carbon 2009, 47, 2-22. [CrossRef]

14. Kar, G.P.; Biswas, S.; Rohini, R.; Bose, S. Tailoring the dispersion of multiwall carbon nanotubes in co-continuous pvdf/abs blends to design materials with enhanced electromagnetic interference shielding. J. Mater. Chem. A 2015, 3, 7974-7985. [CrossRef]

15. Saini, P.; Choudhary, V.; Singh, B.P.; Mathur, R.B.; Dhawan, S.K. Enhanced microwave absorption behavior of polyaniline-cnt/polystyrene blend in 12.4-18.0ghz range. Synth. Met. 2011, 161, 1522-1526. [CrossRef]

16. Joseph, N.; Janardhanan, C.; Sebastian, M.T. Electromagnetic interference shielding properties of butyl rubber-single walled carbon nanotube composites. Compos. Sci. Technol. 2014, 101, 139-144. [CrossRef]

17. Li, L.-y.; Li, S.-I.; Shao, Y.; Dou, R.; Yin, B.; Yang, M.-B. Pvdf/ps/hdpe/mwcnts/fe3o4 nanocomposites: Effective and lightweight electromagnetic interference shielding material through the synergetic effect of mwcnts and fe3o4 nanoparticles. Curr. Appl. Phys. 2018, 18, 388-396. [CrossRef]

18. Huang, C.-Y.; Wu, C.-C. The emi shielding effectiveness of pc/abs/nickel-coated-carbon-fibre composites. Eur. Polym. J. 2000, 36, 2729-2737. [CrossRef]

19. Huang, C.-Y.; Pai, J.-F. Studies on processing parameters and thermal stability of encf/abs composites for emi shielding. J. Appl. Polym. Sci. 1997, 63, 115-123. [CrossRef]

20. Rostami, A.; Masoomi, M.; Fayazi, M.J.; Vahdati, M. Role of multiwalled carbon nanotubes (mwcnts) on rheological, thermal and electrical properties of pc/abs blend. RSC Adv. 2015, 5, 32880-32890. [CrossRef]

21. Jyoti, J.; Basu, S.; Singh, B.P.; Dhakate, S.R. Superior mechanical and electrical properties of multiwall carbon nanotube reinforced acrylonitrile butadiene styrene high performance composites. Compos. Part B Eng. 2015, 83, 58-65. [CrossRef]

22. Schmitz, D.P.; Ecco, L.G.; Dul, S.; Pereira, E.C.L.; Soares, B.G.; Barra, G.M.O.; Pegoretti, A. Electromagnetic interference shielding effectiveness of abs carbon-based composites manufactured via fused deposition modelling. Mater. Today Commun. 2018, 15, 70-80. [CrossRef]

23. Ecco, L.; Dul, S.; Schmitz, D.; Barra, G.; Soares, B.; Fambri, L.; Pegoretti, A. Rapid prototyping of efficient electromagnetic interference shielding polymer composites via fused deposition modeling. Appl. Sci. 2018, 9, 37. [CrossRef]

24. Dimitrov, D.; Schreve, K.; Beer, N.D. Advances in three dimensional printing - state of the art and future perspectives. Rapid Prototyp. J. 2006, 12, 136-147. [CrossRef]

25. Krawczak, P. Additive manufacturing of plastic and polymer composite parts: Promises and challenges of 3d-printing. Express Polym. Lett. 2015, 9, 959. [CrossRef]

26. Durgun, I.; Ertan, R. Experimental investigation of fdm process for improvement of mechanical properties and production cost. Rapid Prototyp. J. 2014, 20, 228-235. [CrossRef]

27. Parandoush, P.; Lin, D. A review on additive manufacturing of polymer-fiber composites. Compos. Struct. 2017, 182, 36-53. [CrossRef] 
28. Li, J.; Wong, P.-S.; Kim, J.-K. Hybrid nanocomposites containing carbon nanotubes and graphite nanoplatelets. Mater. Sci. Eng. A 2008, 483, 660-663. [CrossRef]

29. Yang, S.-Y.; Lin, W.-N.; Huang, Y.-L.; Tien, H.-W.; Wang, J.-Y.; Ma, C.-C.M.; Li, S.-M.; Wang, Y.-S. Synergetic effects of graphene platelets and carbon nanotubes on the mechanical and thermal properties of epoxy composites. Carbon 2011, 49, 793-803. [CrossRef]

30. Wang, P.-N.; Hsieh, T.-H.; Chiang, C.-L.; Shen, M.-Y. Synergetic effects of mechanical properties on graphene nanoplatelet and multiwalled carbon nanotube hybrids reinforced epoxy/carbon fiber composites. J. Nanomater. 2015, 2015, 9. [CrossRef]

31. Ivanov, E.; Kotsilkova, R.; Xia, H.; Chen, Y.; Donato, R.K.; Donato, K.; Godoy, A.P.; Di Maio, R.; Silvestre, C.; Cimmino, S.; et al. Pla/graphene/mwcnt composites with improved electrical and thermal properties suitable for fdm 3d printing applications. Appl. Sci. 2019, 9, 1209. [CrossRef]

32. Spinelli, G.; Lamberti, P.; Tucci, V.; Kotsilkova, R.; Tabakova, S.; Ivanova, R.; Angelova, P.; Angelov, V.; Ivanov, E.; Di Maio, R.; et al. Morphological, rheological and electromagnetic properties of nanocarbon/poly(lactic) acid for 3d printing: Solution blending vs. Melt mixing. Materials 2018, 11, 2256. [CrossRef] [PubMed]

33. Spinelli, G.; Lamberti, P.; Tucci, V.; Kotsilkova, R.; Ivanov, E.; Menseidov, D.; Naddeo, C.; Romano, V.; Guadagno, L.; Adami, R.; et al. Nanocarbon/poly(lactic) acid for 3d printing: Effect of fillers content on electromagnetic and thermal properties. Materials 2019, 12, 2369. [CrossRef] [PubMed]

34. Yuan, D.; Pedrazzoli, D.; Manas-Zloczower, I. Synergistic effects in thermoplastic polyurethanes incorporating hybrid carbon nanofillers. Int. Polym. Process. 2016, 31, 554-561. [CrossRef]

35. Gonçalves, J.; Lima, P.; Krause, B.; Pötschke, P.; Lafont, U.; Gomes, J.; Abreu, C.; Paiva, M.; Covas, J. Electrically conductive polyetheretherketone nanocomposite filaments: From production to fused deposition modeling. Polymers 2018, 10, 925. [CrossRef] [PubMed]

36. Daniel, F.; Patoary, N.H.; Moore, A.L.; Weiss, L.; Radadia, A.D. Temperature-dependent electrical resistance of conductive polylactic acid filament for fused deposition modeling. Int. J. Adv. Manuf. Technol. 2018, 99, 1215-1224. [CrossRef]

37. Dul, S.; Fambri, L.; Pegoretti, A. Fused deposition modelling with abs-graphene nanocomposites. Compos. Part A Appl. Sci. Manuf. 2016, 85, 181-191. [CrossRef]

38. Dorigato, A.; Moretti, V.; Dul, S.; Unterberger, S.H.; Pegoretti, A. Electrically conductive nanocomposites for fused deposition modelling. Synth. Met. 2017, 226, 7-14. [CrossRef]

39. Dul, S.; Fambri, L.; Pegoretti, A. Filaments production and fused deposition modelling of abs/carbon nanotubes composites. Nanomaterials 2018, 8, 49-73.

40. Dul, S.; Pegoretti, A.; Fambri, L. Effects of the nanofillers on physical properties of acrylonitrile-butadiene-styrene nanocomposites: Comparison of graphene nanoplatelets and multiwall carbon nanotubes. Nanomaterials 2018, 8, 674. [CrossRef]

41. Versalis, S.P.A. sinkral@f 322- abs Product Data. Available online: https://www.Materialdatacenter.Com/ms/ en/sinkral/versalis+s\%252ep\%252ea/sinkral\%c2\%ae+f+332/c6da6726/1895 (accessed on 15 April 2019).

42. Xg Sciences (2017) xgnp@Graphene Nanoplatelets Grade M Product Data. Available online: https: //xgsciences.Com/materials/graphene-nano-platelets (accessed on 15 April 2019).

43. Nanocyl@7000tm (2016) Multiwall Carbon Nanotubes Product Data. Available online: http://www.Nanocyl. Com/wp-content/uploads/2016/07/dm-ti-02-tds-nc7000-v08.Pdfxg (accessed on 15 April 2019).

44. Dul, S.; Fambri, L.; Merlini, C.; Barra, G.M.O.; Bersani, M.; Vanzetti, L.; Pegoretti, A. Effect of graphene nanoplatelets structure on the properties of acrylonitrile-butadiene-styrene composites. Polym. Compos. 2019, 40, E285-E300. [CrossRef]

45. Shokrieh, M.M.; Esmkhani, M.; Shahverdi, H.R.; Vahedi, F. Effect of graphene nanosheets (gns) and graphite nanoplatelets (gnp) on the mechanical properties of epoxy nanocomposites. Sci. Adv. Mater. 2013, 5, 260-266. [CrossRef]

46. Batakliev, T.; Georgiev, V.; Ivanov, E.; Kotsilkova, R.; Di Maio, R.; Silvestre, C.; Cimmino, S. Nanoindentation analysis of $3 \mathrm{~d}$ printed poly(lactic acid)-based composites reinforced with graphene and multiwall carbon nanotubes. J. Appl. Polym. Sci. 2019, 136, 47260. [CrossRef]

47. Dul, S.; Pegoretti, A.; Fambri, L. Fused filament fabrication of piezoresistive carbon nanotubes nanocomposites for strain monitoring. Front. Mater. 2020, in press. 
48. Ramôa, S.D.A.S.; Barra, G.M.O.; Merlini, C.; Schreiner, W.H.; Livi, S.; Soares, B.G. Production of montmorillonite/polypyrrole nanocomposites through in situ oxidative polymerization of pyrrole: Effect of anionic and cationic surfactants on structure and properties. Appl. Clay Sci. 2015, 104, 160-167. [CrossRef]

49. Soares, B.G.; Leyva, M.E.; Barra, G.M.O.; Khastgir, D. Dielectric behavior of polyaniline synthesized by different techniques. Eur. Polym. J. 2006, 42, 676-686. [CrossRef]

50. Sachdev, V.K.; Sharma, S.K.; Tomar, M.; Gupta, V.; Tandon, R.P. Emi shielding of mwcnt/abs nanocomposites in contrast to graphite/abs composites and mwcnt/ps nanocomposites. RSC Adv. 2016, 6, 45049-45058. [CrossRef]

51. Sachdev, V.K.; Patel, K.; Bhattacharya, S.; Tandon, R.P. Electromagnetic interference shielding of graphite/acrylonitrile butadiene styrene composites. J. Appl. Polym. Sci. 2011, 120, 1100-1105. [CrossRef]

52. Gao, C.; Zhang, S.; Wang, F.; Wen, B.; Han, C.; Ding, Y.; Yang, M. Graphene networks with low percolation threshold in abs nanocomposites: Selective localization and electrical and rheological properties. ACS Appl. Mater. Interfaces 2014, 6, 12252-12260. [CrossRef]

53. Heo, C.; Moon, H.-G.; Yoon, C.S.; Chang, J.-H. Abs nanocomposite films based on functionalized-graphene sheets. J. Appl. Polym. Sci. 2012, 124, 4663-4670. [CrossRef]

54. Hong, N.; Zhan, J.; Wang, X.; Stec, A.A.; Richard Hull, T.; Ge, H.; Xing, W.; Song, L.; Hu, Y. Enhanced mechanical, thermal and flame retardant properties by combining graphene nanosheets and metal hydroxide nanorods for acrylonitrile-butadiene-styrene copolymer composite. Compos. Part A Appl. Sci. Manuf. 2014, 64, 203-210. [CrossRef]

55. Dahiya, H.S.; Kishore, N.; Mehra, R.M. Effect of percolation on electrical and dielectric properties of acrylonitrile butadiene styrene/graphite composite. J. Appl. Polym. Sci. 2007, 106, 2101-2110. [CrossRef]

56. Wei, X.; Li, D.; Jiang, W.; Gu, Z.; Wang, X.; Zhang, Z.; Sun, Z. 3d printable graphene composite. Sci. Rep. 2015, 5, 11181. [CrossRef] [PubMed]

57. Pandey, A.K.; Kumar, R.; Kachhavah, V.S.; Kar, K.K. Mechanical and thermal behaviours of graphite flake-reinforced acrylonitrile-butadiene-styrene composites and their correlation with entanglement density, adhesion, reinforcement and c factor. RSC Adv. 2016, 6, 50559-50571. [CrossRef]

58. Pour, R.H.; Hassan, A.; Soheilmoghaddam, M.; Bidsorkhi, H.C. Mechanical, thermal, and morphological properties of graphene reinforced polycarbonate/acrylonitrile butadiene styrene nanocomposites. Polym. Compos. 2016, 37, 1633-1640. [CrossRef]

59. Zhang, D.; Chi, B.; Li, B.; Gao, Z.; Du, Y.; Guo, J.; Wei, J. Fabrication of highly conductive graphene flexible circuits by $3 d$ printing. Synth. Met. 2016, 217, 79-86. [CrossRef]

60. Gnanasekaran, K.; Heijmans, T.; van Bennekom, S.; Woldhuis, H.; Wijnia, S.; de With, G.; Friedrich, H. 3d printing of cnt- and graphene-based conductive polymer nanocomposites by fused deposition modeling. Appl. Mater. Today 2017, 9, 21-28. [CrossRef]

61. Chatterjee, S.; Nüesch, F.A.; Chu, B.T.T. Comparing carbon nanotubes and graphene nanoplatelets as reinforcements in polyamide 12 composites. Nanotechnology 2011, 22, 275714. [CrossRef]

62. Al-Saleh, M.H.; Al-Anid, H.K.; Hussain, Y.A. Cnt/abs nanocomposites by solution processing: Proper dispersion and selective localization for low percolation threshold. Compos. Part A Appl. Sci. Manuf. 2013, 46, 53-59. [CrossRef]

63. Wu, C.S.; Liao, H.T. Interface design of environmentally friendly carbon nanotube-filled polyester composites: Fabrication, characterisation, functionality and application. Express Polym. Lett. 2017, 11, 187-198. [CrossRef]

64. Zhang, J.; Yang, B.; Fu, F.; You, F.; Dong, X.; Dai, M. Resistivity and its anisotropy characterization of 3d-printed acrylonitrile butadiene styrene copolymer (abs)/carbon black (cb) composites. Appl. Sci. 2017, 7, 20. [CrossRef]

65. Kotsilkova, R.; Petrova-Doycheva, I.; Menseidov, D.; Ivanov, E.; Paddubskaya, A.; Kuzhir, P. Exploring thermal annealing and graphene-carbon nanotube additives to enhance crystallinity, thermal, electrical and tensile properties of aged poly(lactic) acid-based filament for 3d printing. Compos. Sci. Technol. 2019, 181, 107712. [CrossRef]

(C) 2020 by the authors. Licensee MDPI, Basel, Switzerland. This article is an open access article distributed under the terms and conditions of the Creative Commons Attribution (CC BY) license (http://creativecommons.org/licenses/by/4.0/). 